Estudios Geológicos, 68(1) enero-junio 2012, 5-27

ISSN: $0367-0449$

doi:10.3989/egeol.40918.179

\title{
La erupción submarina de La Restinga en la isla de El Hierro, Canarias: Octubre 2011-Marzo 2012
}

\section{The submarine eruption of La Restinga (El Hierro, Canary Islands): October 2011-March 2012}

\author{
F.J. Perez-Torrado ${ }^{1}$, J.C. Carracedo ${ }^{1}$, A. Rodriguez-Gonzalez ${ }^{1}$, V. Soler ${ }^{2}$, V.R. Troll ${ }^{3}$, \\ S. Wiesmaier ${ }^{4}$
}

\begin{abstract}
RESUMEN
Los primeros indicios de una posible erupción volcánica en El Hierro se percibieron a partir de julio de 2011 en forma de sismos de baja intensidad pero anormalmente numerosos. La intensificación de la sismicidad culminó con el inicio de la erupción submarina el 10 de octubre de 2011 a unos 2 km al sur de La Restinga. La sismicidad y deformación del terreno que precedieron y acompañaron a esta erupción han permitido reconstruir las principales fases de actividad volcánica: 1) generación y ascenso del magma con migración de los hipocentros sísmicos desde el norte, en el Golfo, hasta el rift sur, en La Restinga, marcando la apertura hidráulica del conducto magmático; y 2) inicio y continuidad de la erupción volcánica evidenciada por un tremor armónico continuo de intensidad variable en el tiempo. Las características observadas a lo largo de la erupción, principalmente localización, profundidad y evolución morfológica del foco emisor, así como emisión de materiales volcánicos flotantes, inicialmente con un núcleo blanco poroso (procedentes de la fusión parcial de sedimentos de la capa superior de la corteza oceánica anteriores a la construcción del edificio insular de El Hierro) envuelto por una corteza basanítica y después huecas (lava balloons), se han correspondido con una erupción submarina fisural profunda sin que nunca hayan intervenido mecanismos más explosivos tipo surtseyano. La erupción se mantuvo activa durante unos cinco meses, dándose por finalizada en marzo del 2012, convirtiéndose de este modo en la segunda erupción histórica más longeva de Canarias después de la de Timanfaya (1730-36) en Lanzarote. Esta erupción ha supuesto la primera oportunidad en 40 años de gestionar una crisis volcánica en Canarias y de analizar las observaciones e interpretaciones y las decisiones adoptadas, con objeto de mejorar la gestión de futuras crisis volcánicas. El Instituto Geográfico Nacional (IGN) se encargó de adquirir y analizar la información sísmica y de deformación durante todo el proceso. Sin embargo, no se dispuso inicialmente de un barco oceanográfico que realizara estudios sistemáticos de la profundidad y progresión de la erupción, así como de toma de muestras de los materiales emitidos (piroclastos y lavas), elementos claves para la determinación de la peligrosidad eruptiva. Estas deficiencias en el seguimiento científico del proceso eruptivo dificultaron en algunos momentos la toma de decisiones de protección civil. El análisis de la crisis ha puesto de manifiesto que, aunque se disponga de una infraestructura técnica adecuada para la detección temprana de crisis eruptivas en el archipiélago, de poco valen las medidas administrativas planificadas sin un seguimiento científico continuo e integrador del proceso eruptivo, abierto a la colaboración científica nacional e internacional.
\end{abstract}

Palabras claves: erupción volcánica submarina, rift sur, gestión crisis volcánica, El Hierro, Islas Canarias.

\section{ABSTRACT}

The first signs of renewed volcanic activity at El Hierro began in July 2011 with the occurrence of abundant, low-magnitude earthquakes. The increasing seismicity culminated on October 10, 2011, with

\footnotetext{
1 Grupo investigación GEOVOL, Dpto. de Física, Universidad de Las Palmas de Gran Canaria, España. Email: fperez@dfis.ulpgc.es; jcarracedo@proyinves.ulpgc.es; arodriguez@proyinves.ulpgc.es

2 Estación Volcanológica de Canarias, IPNA-CSIC, La Laguna, Tenerife, España. Email: vsoler@ipna.csic.es

3 Dept. of Earth Sciences, CEMPEG, Uppsala University, Sweden. Email: valentine.troll@geo.uu.es

4 Dept. of Earth and Environmental Sciences, Ludwig-Maximilians Universität, Munich, Germany. Email:

sebastian.wiesmaier@min.uni-muenchen.de
} 


\begin{abstract}
the onset of a submarine eruption about $2 \mathrm{~km}$ offshore from La Restinga, the southernmost village on EI Hierro. The analysis of seismic and deformation records prior to, and throughout, the eruption allowed the reconstruction of its main phases: 1) ascent of magma and migration of hypocentres from beneath the northern coast (El Golfo) towards the south rift zone, close to La Restinga, probably marking the hydraulic fracturing and the opening of the eruptive conduit; and 2) onset and development of a volcanic eruption indicated by sustained and prolonged harmonic tremor whose intensity varied with time. The features monitored during the eruption include location, depth and morphological evolution of the eruptive source and emission of floating volcanic bombs. These bombs initially showed white, vesiculated cores (originated by partial melting of underlying pre-volcanic sediments upon which the island of El Hierro was constructed) and black basanite rims, and later exclusively hollow basanitic lava balloons. The eruptive products have been matched with a fissural submarine eruption without ever having attained surtseyan explosiveness. The eruption has been active for about five months and ended in March 2012, thus becoming the second longest reported historical eruption in the Canary Islands after the Timanfaya eruption in Lanzarote (1730-1736). This eruption provided the first opportunity in 40 years to manage a volcanic crisis in the Canary Islands and to assess the interpretations and decisions taken, thereby gaining experience for improved management of future volcanic activity. Seismicity and deformation during the eruption were recorded and analysed by the Instituto Geográfico Nacional (IGN). Unfortunately, a lack of systematic sampling of erupted pyroclasts and lavas, as well as the sporadic monitoring of the depth and growth of the submarine vent by deployment of a research vessel, hampered a comprehensive assessment of hazards posed during volcanic activity. Thus, available scientific data and advice were not as high quality as they could have been, thereby limiting the authorities in making the proper decisions at crucial points during the crisis. The response in 2011-12 to the El Hierro eruption has demonstrated that adequate infrastructure and technical means exist in the Canary Islands for the early detection of potential eruptive hazards. However, it also has taught us that having detailed emergency management plans may be of limited value without an accompanying continuous, well-integrated scientific monitoring effort (open to national and international collaboration) during all stages of an eruption.
\end{abstract}

Key words: submarine volcanic eruption, south rift zone, emergency management, El Hierro, Canary Islands.

\section{Introducción}

La isla de El Hierro, con apenas 1,2 Ma de edad, es la más joven del Archipiélago Canario. Esta juventud geológica, puesta de manifiesto no solamente en la geocronología de sus formaciones volcánicas, sino en el propio paisaje, estructuras geológicas predominantes, etc., contrasta con la ausencia de erupciones subaéreas en tiempos históricos. En este escenario, la erupción submarina de 201112 al sur de La Restinga ha corroborado los conocimientos geológicos previos que se tienen de esta isla y, en general, de Canarias, remarcando tres aspectos claves: i) se produce en la isla geológicamente más joven, actualmente en la vertical de la anomalía térmica del manto que ha generado el Archipiélago Canario; ii) es submarina, lo que está en consonancia con el mayor volumen submarino de las islas (en el caso de El Hierro, más del 90\% de su volumen se localiza bajo el mar) y iii) se ha localizado en el rift sur, estructura que concentra un volumen importante de las erupciones más recientes de la isla.

El objetivo de este trabajo es presentar una interpretación geológica de la erupción submarina ocurrida en El Hierro (octubre 2011-marzo 2012) en base a la información sísmica y de deformación del terreno obtenida por el Instituto Geográfico Nacional (IGN; http://www.ign.es/ign/resources/volcanologia/HIERRO.html), los datos batimétricos adquiridos por el Instituto Español de Ocenografía (IEO; http://www.ieo.es/hierro.htm) y al conocimiento previo sobre su volcanismo (Guillou et al., 1996; Carracedo et al., 2001). Asimismo, se discutirán los aspectos más destacados en el seguimiento y gestión de esta crisis sismo-volcánica, a fin de introducir mejoras en la gestión de futuros eventos.

Consideraciones complementarias sobre esta erupción submarina en El Hierro se pueden encontrar en Carracedo et al. (2011), Carracedo et al. (2012a) y Carracedo et al. (2012b).

\section{La erupción submarina de 2011-12 en el contexto geológico de El Hierro}

La isla de El Hierro es la más occidental y joven del Archipiélago Canario. La edad más antigua obtenida en las formaciones emergidas de la isla es de 1,12 Ma (Guillou et al., 1996), correspondiente al primero de los edificios volcánicos en escudo (Tiñor) que, superpuestos, forman la isla (Fig. 1A). Con posterioridad al colapso lateral de la parte norte del escudo basáltico de Tiñor, hace aproximada- 

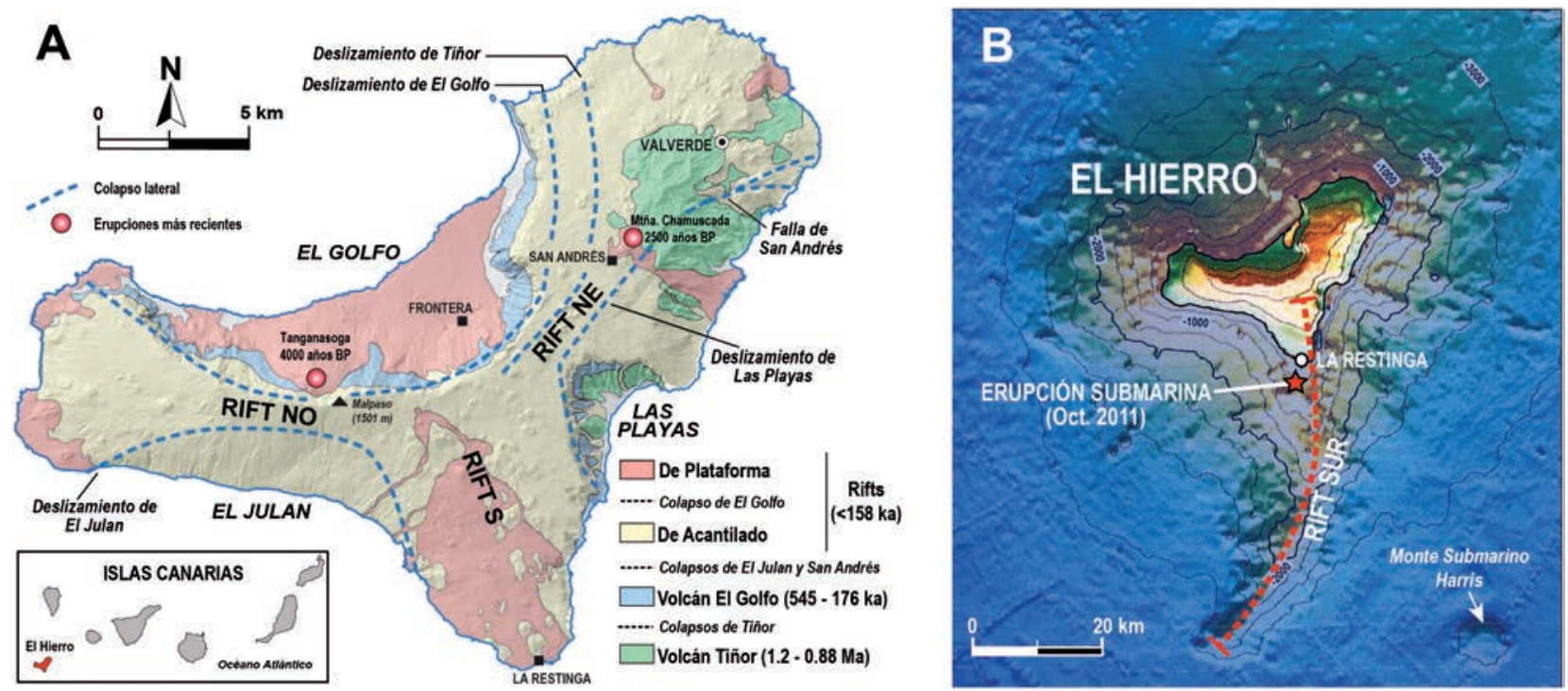

Fig. 1.-A) Mapa geológico de El Hierro (modificado de Carracedo et al., 2001). B) Edificio insular de El Hierro mostrando la relación de la estructura submarina respecto a la emergida (basada en Masson et al., 2002). La erupción (señalada con una estrella) se emplazó en la prolongación submarina del rift S.

mente $880 \mathrm{ka}$, la cuenca formada fue rellenada por otro escudo basáltico -El Golfo-, que colapsó asimismo hace unos 130-80 ka (Longpre et al., 2011). Posteriormente, el volcanismo de El Hierro se ha concentrado en un sistema triple de dorsales o rifts (NO, NE y S), que se prolongan en la parte submarina del edificio insular, particularmente en el rift $S$ (Fig. 1 B). Una detallada información sobre la geocronología de sus formaciones volcánicas puede encontrarse en Guillou et al. (1996), y sobre su estratigrafía y evolución geológica en Carracedo et al. (2001).

En resumen, la evolución geológica de la isla de El Hierro indica que se encuentra en el primer estadio de desarrollo subaéreo coherente con su posición en la vertical de la anomalía térmica del manto que ha generado el Archipiélago Canario (Carracedo et al., 1998, 2001, 2002).

\section{Volcanismo holoceno y crisis sísmica de 1793}

A pesar de ser la isla más joven de Las Canarias, El Hierro no tiene volcanismo histórico subaéreo, que sí existe en La Palma, Tenerife e incluso Lanzarote. Una explicación de esta aparente paradoja puede consistir en que El Hierro y La Palma forman una alineación doble y están creciendo de forma simultánea, a diferencia de las restantes islas del archipiélago, que comienzan a formarse cuando la anterior está muy desarrollada. Sin embargo, aunque ambas islas comparten el periodo juvenil de desarrollo, no parecen hacerlo de forma continua, sino en fases alternantes ("on-off"), predominando la actividad volcánica en una isla mientras la otra permanece esencialmente en reposo eruptivo (Carracedo et al., 1998, 2001).

En el Holoceno, la fase de mayor actividad corresponde a La Palma, lo que explica la existencia en esta isla de decenas de erupciones volcánicas en este periodo, 6 de ellas históricas ( $<500$ años). En cambio, en la isla de El Hierro la actividad volcánica subaérea holocena es algo más reducida, siendo la erupción de Montaña Chamuscada, emplazada en el rift NE cerca de la localidad de San Andrés, la más reciente datada hasta la fecha con una edad de $2500 \pm 70$ años (Guillou et al., 1996). La siguiente erupción en juventud probablemente se corresponda con la del complejo volcánico del Tanganasoga, emplazado en el rift NO y con una edad algo menor de 4000 años (Pellicer, 1979; PerezTorrado et al., 2011).

Terremotos de considerable magnitud (probablemente mayores que los de la erupción de 2011-12) sacudieron la isla de El Hierro entre el 27 de marzo y el 15 de junio de 1793, destruyendo edificios y provocando gran temor en la población. Temiéndose una gran catástrofe (una erupción volcánica), se llegó incluso a elaborar el primer plan de evacuación de una isla en la historia de Canarias, que com- 

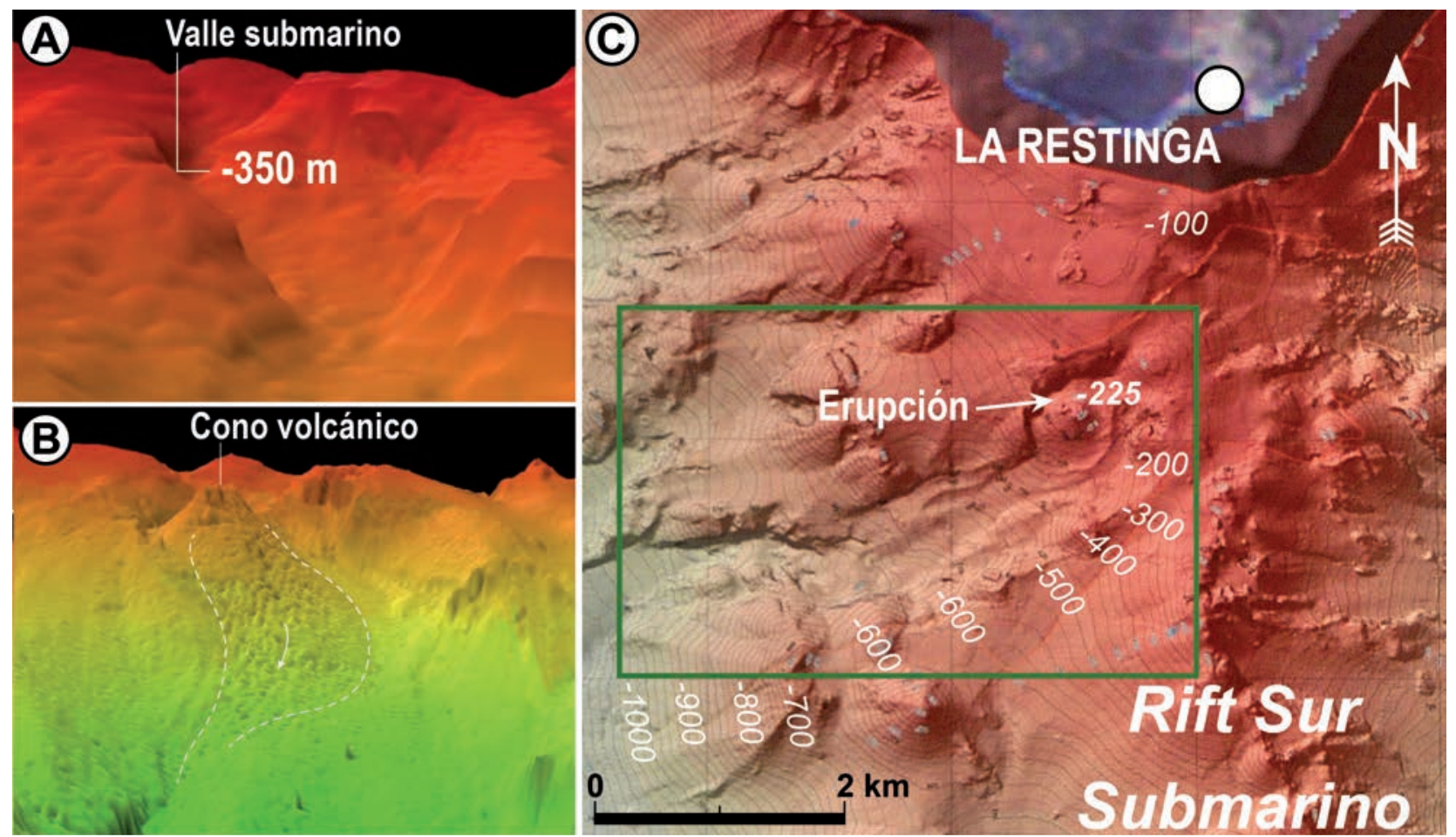

Fig. 2.-Batimetría de la zona de la erupción submarina realizada mediante ecosondas por distintos buques oceanográficos (imágenes tomadas del IEO). A) Imagen 3D de la batimetría anterior a la erupción, realizada por el B/O Hespérides (CSIC) en 1998. B) Idem por el B/O Ramón Margalef después de iniciada la erupción submarina, el 24 de octubre de 2011. C) Mapa en relieve de la zona de la erupción realizado por el B/O Ramón Margalef el 24 de octubre de 2011 . A partir de esta base topográfica se han realizado los mapas de la figura 8 cuyos límites están definidos por el área comprendida en el recuadro.

prendía medidas para la protección de la población. Los temblores de mayor intensidad se registraron en la zona de El Golfo y se extendieron luego a toda la isla. A partir del 8 de mayo fueron de tal intensidad que la población abandonó sus casas y dormía al raso. Todos esperaban de un momento a otro una gran erupción volcánica, pero finalmente los terremotos fueron decreciendo en número e intensidad hasta desaparecer, volviendo la isla a la normalidad sin que se llegara a producir la temida erupción o bien que ésta fuese submarina y sin otra consecuencia apreciable que los terremotos. La crónica de Darias Padrón (1929), donde aparece el relato de esta crisis sísmica de El Hierro, no alude a una erupción, al indicar claramente que las medidas planificadas se hubieran implementado "si el vulcanismo hubiera destruido la isla azotada", sugiriendo que la erupción no llegó a producirse, al menos, en tierra.

Hernández-Pacheco (1982) sugirió, sin embargo, que esta crisis sísmica sí desembocó en una erupción fisural generadora de un campo de lavas basálticas en el lugar denominado Lomo Negro, dentro del área conocida como Hoya del Verodal (en el extremo NO de la isla). Los principales argumentos esgrimidos por el autor fueron la observación de un mínimo grado de alteración en las lavas, la ausencia de vestigios de actividad aborigen ("concheros") en sus numerosas cuevas (formadas por colapsos parciales de tubos volcánicos) y la datación por radiocarbono de restos de vegetales asociados a estas lavas (si bien, el propio autor indicó un origen dudoso para estos restos) con fecha próxima a la crisis sísmica. No obstante, trabajos recientes sobre evolución morfométrica de erupciones holocenas en El Hierro (Rodriguez-Gonzalez et al., 2011) han puesto de manifiesto que el grado de erosión marina de estas lavas de Lomo Negro es similar al de las lavas de los volcanes adyacentes en esa área de Hoya del Verodal, uno de los cuales ha sido datado mediante $\mathrm{K}$-Ar en $8 \pm 2$ ka (Montaña Marcos, $\mathrm{H}$. Guillou, com. pers.), lo que hace incompatible asimilar esta erupción a la crisis sísmica de 1793.

Tal vez la clave para la interpretación de esta crisis sísmica de 1793 se encuentre en la reciente de 2011-12, en el sentido de que si realmente tuvo una 
erupción asociada, ésta pudo ser submarina profunda. Esta posibilidad encajaría mejor con el estadio evolutivo juvenil de la isla, ya que un intervalo de tiempo de varios miles de años (desde los 2500 años en que ha sido datada la erupción de Montaña Chamuscada) sin actividad volcánica resulta poco verosímil, siendo más plausible que en este lapso de tiempo hayan podido ocurrir erupciones submarinas profundas con escasa a nula repercusión en la superficie, como la que ha tenido lugar en 2011-12.

\section{El rift $S$ de El Hierro}

El volcanismo del rift $\mathrm{S}$ comprende la fase más reciente de la actividad eruptiva de la isla, en conjunción con la de los otros dos rifts, NO y NE. En su parte subaérea concentra un importante volcanismo formando plataformas costeras (ver fig. 1A), correspondiente a erupciones posteriores al último máximo glacial (Carracedo et al., 1999, 2001). En cuanto a su prolongación submarina, presenta un recorrido de unos $38 \mathrm{~km}$ de longitud alcanzando profundidades de unos $3700 \mathrm{~m}$. De esta estructura, los 13 primeros $\mathrm{km}$ corresponden a la continuación del rift subaéreo, formando una cresta de $1 \mathrm{~km}$ de altura y flancos con pendientes $>30^{\circ}$; los restantes $25 \mathrm{~km}$ forman una alineación ligeramente curvada al SO (ver fig. 1B), que parece pertenecer a un edificio volcánico más antiguo, al igual que el monte submarino Henry, situado al SE, ambos cubiertos por varios metros de sedimentos (Mitchell, 1993). En campañas oceanográficas en zonas próximas ( $<3 \mathrm{~km}$ de distancia) a la localización de la actual erupción de 2011-12, se dragaron numerosas muestras de lavas (picritas y basaltos alcalinos) e hialoclastitas con escaso grado de alteración, lo que evidencian una edad muy reciente (Mitchell, 1993; Urgeles et al., 1997, 1998; Schmincke et al., 1998; Gee et al., 1999; Ye et al., 1999; Schmincke \& Graf, 2000; Krastel \& Schmincke, 2002; Masson et al., 2002).

La batimetría de la prolongación submarina del rift $\mathrm{S}$ fue generada en 1997 en la campaña CD108 del buque oceanográfico (B/O) inglés Charles Darwin (Masson, 1998), utilizando técnicas de sonar multihaz (ecosonda Simrad EM12) y sísmicas. Posteriormente el B/O Hespérides, del Consejo Superior de Investigaciones Científicas (CSIC), obtuvo en 1998 la batimetría de esta zona en el marco del Programa ZEE (IEO-IHM), con técnicas similares (Fig. 2A). Finalmente, el B/O Ramón Margalef del

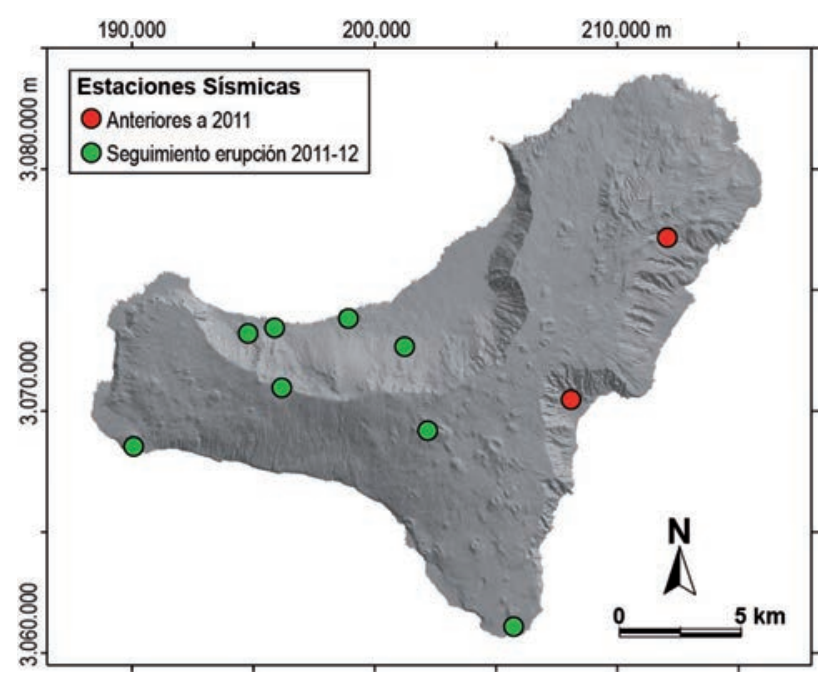

Fig. 3.-Localización de las estaciones sísmicas desplegadas por el IGN para el seguimiento de la actividad precursora y la acompañante de la erupción de El Hierro de 2011-12.

IEO, utilizando instrumentos de mayor precisión (ecosonda multihaz EM-710 y ecosonda multifrecuencias EK-60), logró numerosas batimetrías de alta resolución de este rift submarino en las áreas próximas a la erupción a lo largo de varias de sus campañas oceanográficas (Fig. 2B y 2C).

\section{Evolución de la erupción submarina}

La erupción submarina de El Hierro (2011-12) ha supuesto la última manifestación volcánica en Canarias después de 40 años de inactividad, desde la erupción del Teneguía en la isla de La Palma en 1971. Supone, asimismo, la decimocuarta erupción histórica (últimos 520 años) en Canarias y la primera en la isla de El Hierro con registro fidedigno.

Gracias a la red instrumental desplegada por el IGN y a los levantamientos batimétricos desarrollados por el IEO, principalmente, se han podido estudiar tanto sus manifestaciones precursoras como las ocurridas durante su desarrollo, las cuales se exponen a continuación.

\section{Sismicidad y deformación del terreno}

La sismicidad y otros parámetros (deformación, anomalías gravitatorias, parámetros físico-químicos de las aguas subterráneas, etc.) que han precedido y acompañado a esta erupción, fueron registrados por 

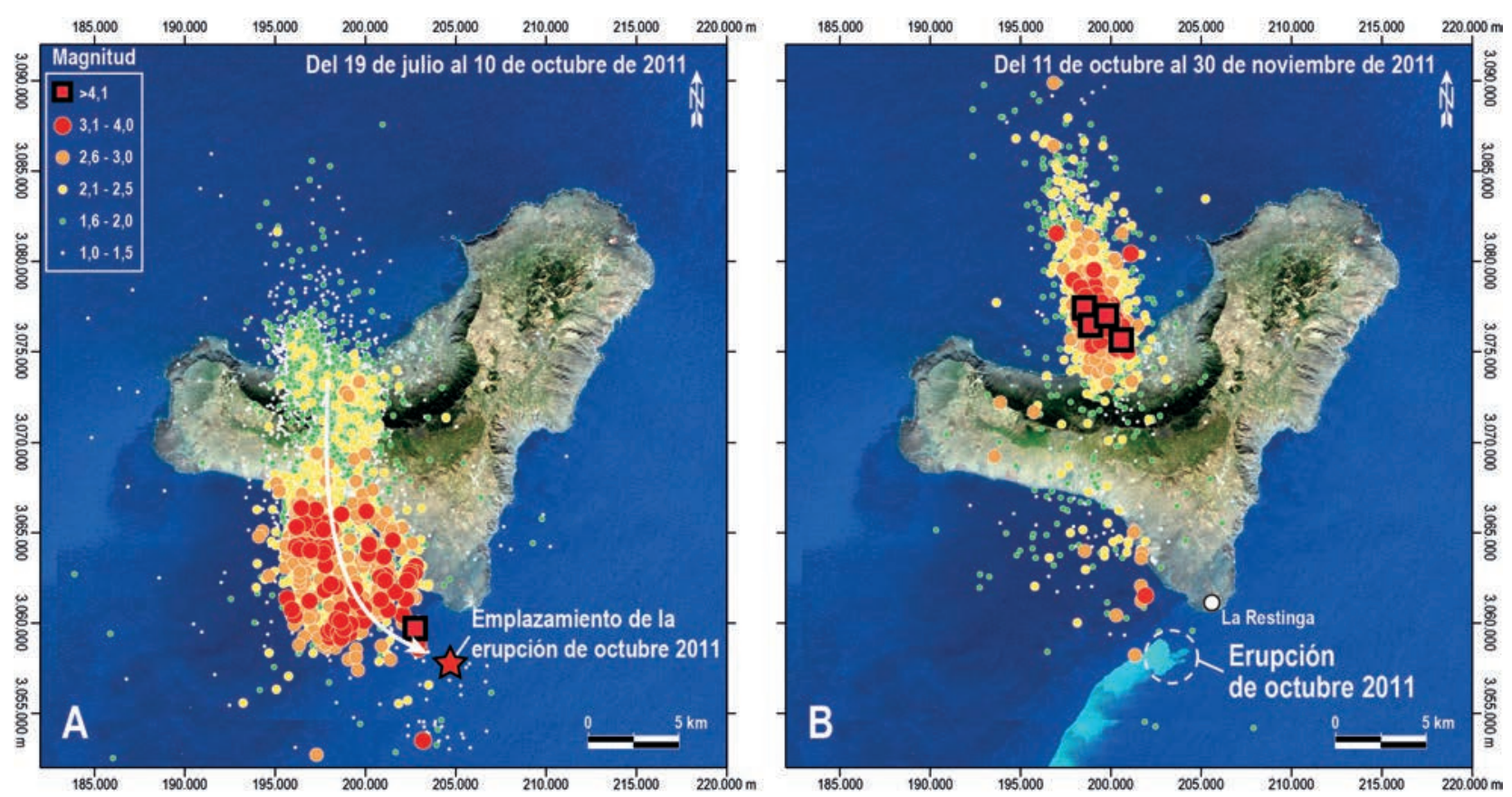

Fig. 4.-Sismicidad asociada a la erupción de El Hierro de 2011 (con datos del IGN). A) Sismicidad precursora, desde el 19 de julio de 2011 hasta el comienzo de la erupción el 10 de octubre. Se marcan las posiciones del terremoto con M 4,4 que generó la fracturación hidraúlica que desencadenó la erupción y del foco eruptivo. B) Idem a partir del comienzo de la erupción hasta el 30 de noviembre de 2011.

el IGN. Antes de la erupción, esta institución tenía en El Hierro una estación sísmica de transmisión digital vía satélite (en la galería Tijirote, al sureste de la isla) y otra de transmisión analógica, en Valverde. Al constatarse la existencia de una situación anómala por la frecuencia de la sismicidad, desplegó una red más densa en toda la isla, incorporando 8 nuevas estaciones en su mitad occidental, principalmente en el valle de El Golfo y rift Sur (Fig. 3). Asimismo, colocaron estaciones geoquímicas (para medidas analíticas en aguas subterráneas en varias galerías y de la desgasificación difusa a través de la isla), de GPS (para la obtención de datos de deformación del terreno, tanto en la componente vertical como en la horizontal), gravimétricas y magnéticas. Esta red instrumental ha permitido por primera vez conocer en detalle la actividad precursora de una erupción volcánica en Canarias.

Desde el mediodía del 19 de julio de 2011 comenzó a registrarse actividad sísmica de baja intensidad (Magnitud $(\mathrm{M})<3$ ) en el norte de la isla, frente al pueblo de Sabinosa (Fig. 4A). Durante el mes de agosto el número de sismos fue aumentando paulatinamente, si bien la profundidad hipocentral (en su mayoría entre 10 y $15 \mathrm{~km}$ ) y magnitud siguió pautas similares por lo que solo unos pocos fueron percibidos por la población. A partir del 20 de septiembre de 2011 la sismicidad aumentó ligeramente, con dos eventos de M 3.4 los días 24 y 25, en el suroeste y norte de la isla, respectivamente. Estos sismos, especialmente el del norte, fueron sentidos claramente por la población (intensidad IV). El incremento de la frecuencia y magnitud continuó durante el resto de septiembre y la primera semana de octubre, con decenas de terremotos sentidos por la población. La noche del 8 de octubre se produjo un terremoto de M 4,4 en el Mar de las Calmas, a unos $3,5 \mathrm{~km}$ al suroeste de La Restinga y con una profundidad hipocentral de unos $15 \mathrm{~km}$, que pudo ser ocasionado por la apertura de una importante fractura hidraúlica al inyectarse el magma en su camino hacia la superficie (Fig. 5). Finalmente, a las 03:15 h del 10 de octubre del 2011 se inició un tremor armónico considerado por el IGN como el inicio de la erupción submarina (Fig. 6A). Esta señal sísmica, aunque con ciertas fluctuaciones en amplitud y frecuencia, ha acompañado a la erupción en todo su desarrollo.

El total de sismos registrados durante todo el periodo pre-eruptivo ascendió a unos 10.000 , de los cuales sólo 95 (registrados a partir del 23 de septiembre) tuvieron magnitudes entre 3,0 y 4,6, aun- 


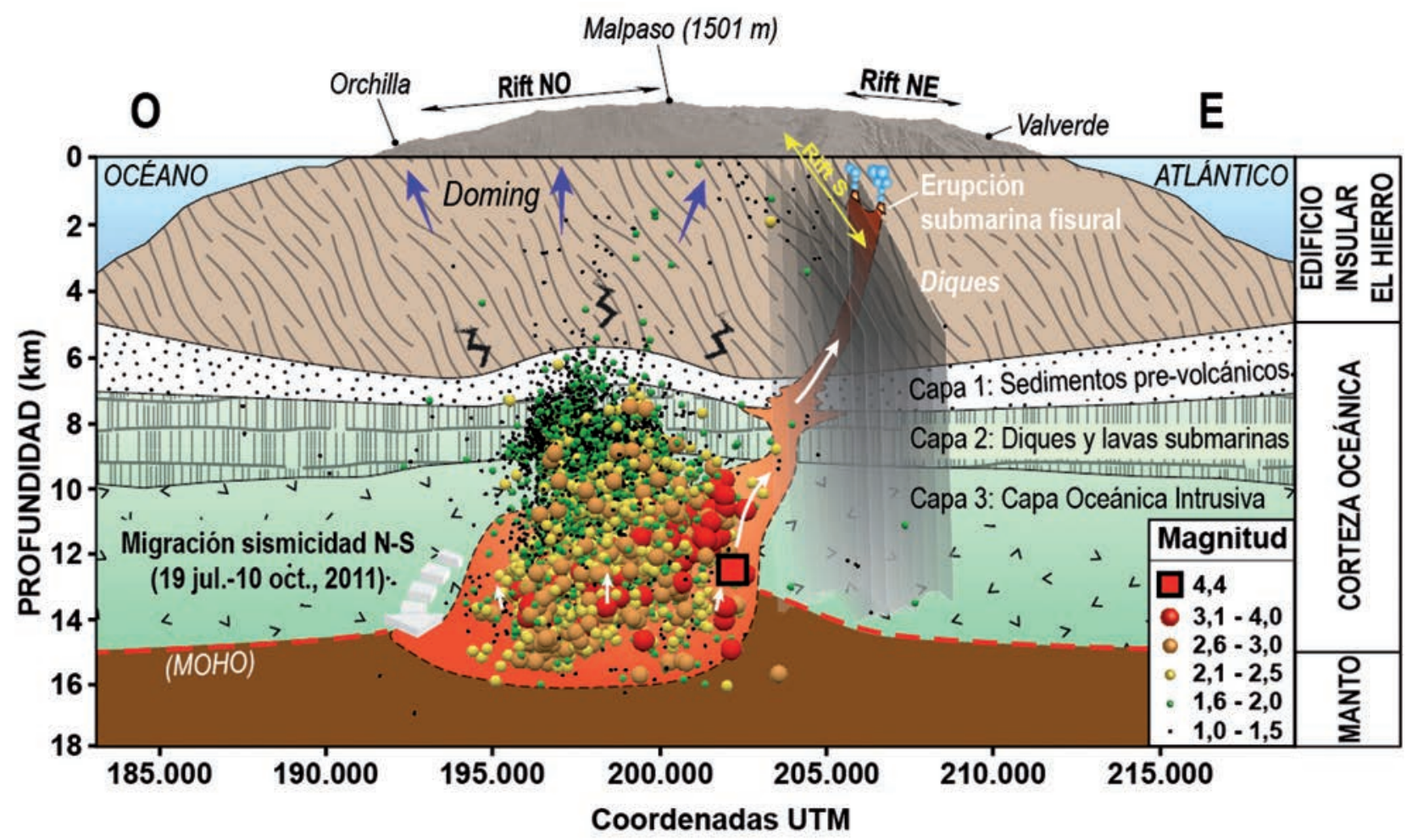

Fig. 5.-Sección E-O de El Hierro mostrando la sismicidad precursora asociada a la erupción de 2011-12, desde el 19 de julio de 2011 hasta el comienzo de la erupción el 10 de octubre (con datos del IGN). Obsérvese la disposición de los hipocentros en la base de la corteza, forzando su abombamiento, y su migración N-S hasta alcanzar el rift S en su flanco sumergido. Los hipocentros emigraron a zonas someras muy rápidamente los días anteriores a la erupción, indicando una fractura hidráulica en camino a la superficie. La erupción fue típicamente fisural, al abrirse camino el magma entre la malla de diques del rift (modificado de Carracedo et al., 2011).

que al tener profundidades hipocentrales superiores a $\operatorname{los} 10 \mathrm{~km}$ no revistieron peligro alguno en la población.

En cuanto a la deformación del terreno medida con estaciones GPS, los valores máximos, tanto en la componente vertical como en la horizontal, se obtuvieron en el área de la isla donde se acumularon los epicentros sísmicos. La deformación vertical alcanzó hasta los $40 \mathrm{~mm}$, mientras que la horizontal fue de unos $50 \mathrm{~mm}$. Esta componente horizontal, además, presentaba direcciones opuestas (hacia el $\mathrm{E}$ y O) a ambos lados del eje principal de la deformación vertical, lo que sugiere la inyección de un cuerpo en forma de domo alargado en la dirección N-S (ver fig. 5).

De acuerdo con los datos del IGN, se observó que desde el comienzo de la crisis (19 julio 2011) hasta el momento de la erupción (10 octubre 2011), los terremotos siguieron una pauta migratoria $\mathrm{N}-\mathrm{S}$, localizándose inicialmente al norte de la isla, en la cuenca de El Golfo, para emplazarse finalmente en la zona de El Julan y el Mar de Las Calmas, al sur de la isla (ver fig. 4A). En cuanto a la localización de sus hipocentros, la mayor parte de ellos se concentraron en la parte inferior de la corteza oceánica, a profundidades de 10-14 km (a una presión de 200$400 \mathrm{MPa}$ ), lo que concuerda con lo indicado en el estudio de inclusiones fluidas microscópicas en xenolitos de la parte NO de El Hierro (Hansteen et $a l ., 1998)$ y en fenocristales de erupciones holocenas (A. Klügel, com. pers.).

Los datos sísmicos, de deformación del terreno y petrológicos concuerdan con un escenario en el que un volumen de magma mantélico ascendió y quedó atrapado cerca o en la base de la corteza oceánica, debido a la trampa de densidad que supone la interfase corteza-manto (la discontinuidad de Mohorovičić). Este estancamiento llegó a generar deformaciones en la vertical del terreno de hasta $40 \mathrm{~mm}$ en algunos sectores de la isla, pero este empuje vertical ejercido por el magma ascendente resultó insuficiente para fracturar la corteza oceánica, por lo que se vio obligado a expandirse lateralmente migrando hacia el S. En esa migración magmática 


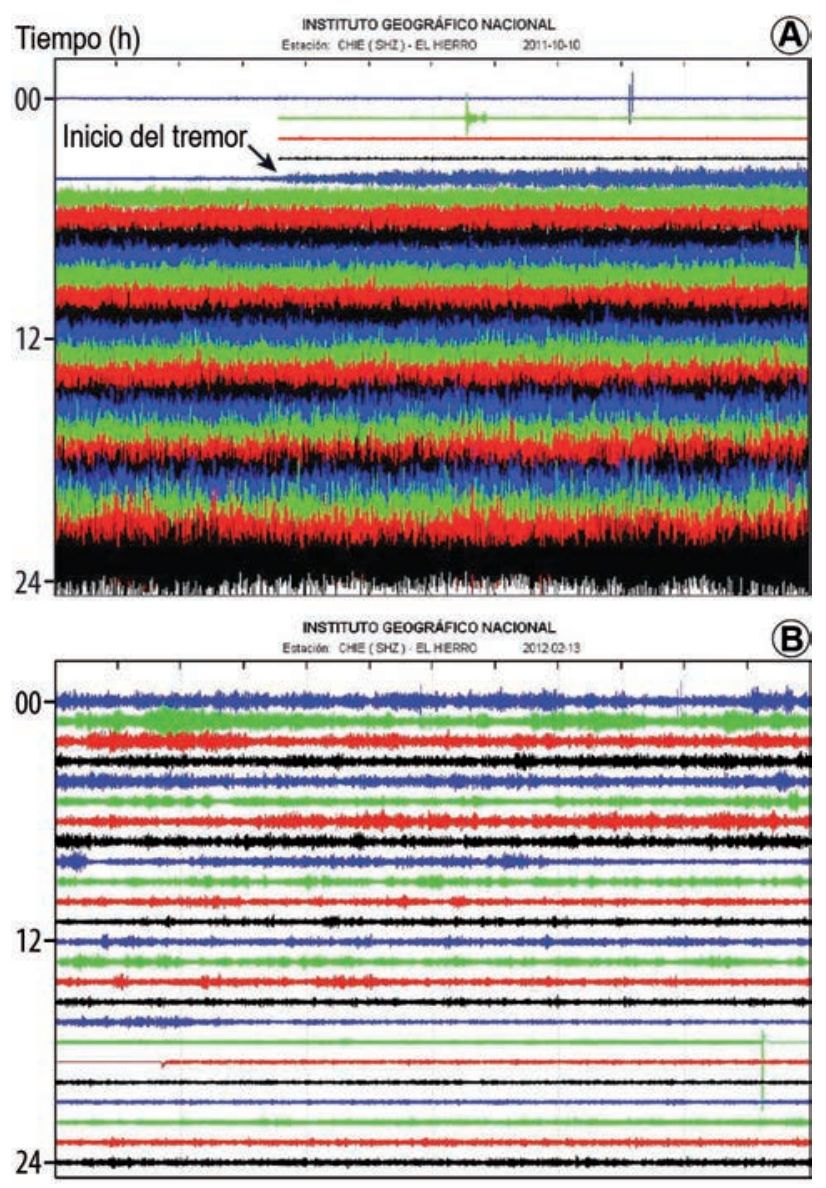

Fig. 6.-A) Tremor armónico marcando el inicio de la erupción submarina a las $3: 15 \mathrm{~h}$ del 10 de octubre (tomado del IGN). B) A partir del 13 de febrero de 2012 el tremor armónico descendió de amplitud marcando el declive de la erupción.

de $\mathrm{N}$ a $\mathrm{S}$ de la isla, el magma cruzó la zona de corteza oceánica afectada por las intrusiones previas que han alimentado el rift NO sin que aparentemente sufriera ningún tipo de alteración en su movimiento. Sin embargo, al alcanzar el área de influencia del rift $\mathrm{S}$ tuvo lugar el terremoto de $\mathrm{M}$ 4,4 lo que permitió al magma atravesar la corteza oceánica, alcanzar el edificio insular y ascender rápidamente (menos de 2 días) a la superficie (ver fig. 5) aprovechando la menor resistencia que suponen las estructuras de los rifts (Carracedo, 1994). Este hecho puede explicar la aparente ausencia de sismicidad somera $(<3-5 \mathrm{~km})$ en este ascenso final del magma.

Una vez iniciada la erupción, la sismicidad volvió a concentrarse en la cuenca de El Golfo, al N de la isla (Fig. 4B), para de nuevo volver a trazar un camino migratorio muy similar al descrito en los meses previos a la erupción. Sin embargo, las profundidades hipocentrales de los sismos describieron un dibujo ligeramente diferente, concentrándose alrededor de los $20 \mathrm{~km}$ para los ubicados al norte de la isla, mientras que los localizados al sur se concentraban alrededor de los $15 \mathrm{~km}$. Estas pautas de distribución de la sismicidad, tanto en planta como en perfil, unidas a las de distribución de la deformación del terreno, pusieron de manifiesto la existencia de una continua realimentación magmática desde el manto superior en la zona norte de la isla (en la cuenca de El Golfo) y un flujo migratorio hacia el foco eruptivo en el sur de la isla (en el Mar de las Calmas) a lo largo de la interfase manto-corteza oceánica. Aunque en esta sismicidad contemporánea con la erupción volcánica se registraron 4 eventos de $M>4$ en la zona norte de la isla, en ningún momento hubo constancia de erupción alguna en este sector ni en ningún otro de la isla aparte del observado al sur de La Restinga.

El total de sismos registrados por el IGN durante el periodo eruptivo fue de unos 2.500 , cifra muy inferior a los 10.000 que se registraron en el periodo pre-eruptivo. Sin embargo, el número de sismos con magnitudes entre 3,0 y 4,6 (todos ellos ocurridos en los dos primeros meses de la erupción, octubre y noviembre de 2011) es proporcionalmente mayor, contabilizándose un total de 54, todos ellos con profundidades hipocentrales superiores a los $10 \mathrm{~km}$.

En cuanto a la señal del tremor, empezó a tener notables decrecimientos en amplitud a finales de noviembre de 2011, pero es a partir del 13 de febrero de 2012 cuando se hace muy plana (Fig. 6B) Este hecho, unido a la medición de otros parámetros (p. ej., los valores de deformación del terreno estabilizados desde el mes de noviembre de 2011, comenzaron en algunas estaciones GPS a marcar una tendencia deflacionista), hicieron que las autoridades encargadas del seguimiento de esta crisis volcánica determinaran el final de la erupción con fecha de 5 de marzo de 2012 (Gobierno de Canarias, 2012. Comunicado de prensa de 5 de marzo 2012).

\section{Evolución morfológica del área eruptiva}

Aparte del tremor armónico no hubo evidencia directa de la existencia de la erupción submarina hasta que se emitieron las primeras columnas de gases con material en suspensión (12 de octubre) y hasta la llegada a la superficie del mar de los prime- 

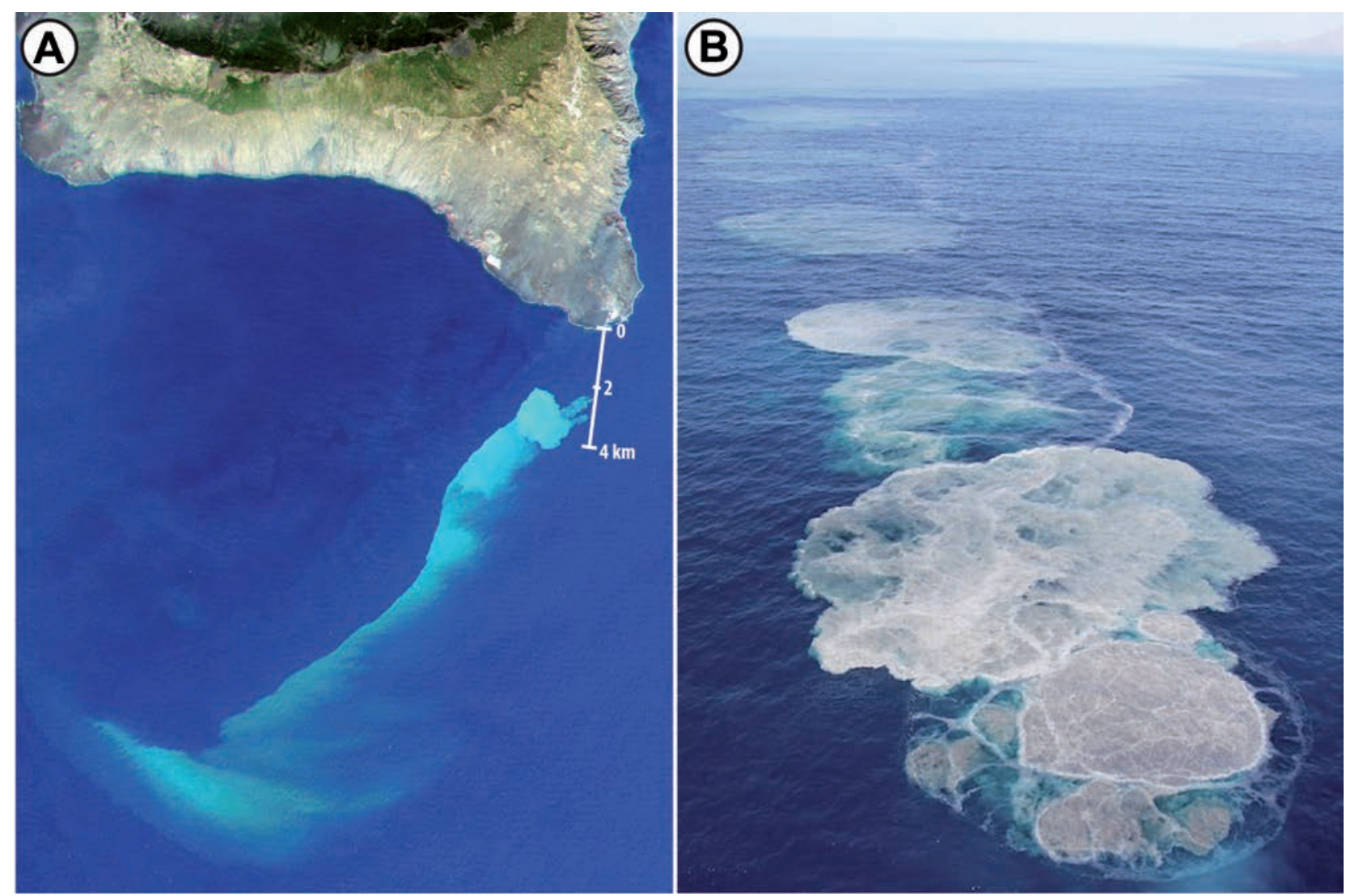

Fig. 7.- Surgencia de gases y piroclastos en la erupción submarina. A) Localización de las bocas eruptivas por las surgencias de gases y sedimentos oceánicos removidos (imagen del satélite RapidEye del 13 de octubre, 2011). B) Las surgencias muestran claramente el carácter fisural de la erupción submarina (fotografía tomada por el helicóptero de la Guardia Civil el 4 de noviembre de 2011).

ros materiales volcánicos flotantes (15 de octubre). Asimismo, su ubicación exacta se consiguió cuando el B/O Ramón Margalef del IEO realizó su primera batimetría el 24 de octubre. En consecuencia, no hay datos de esta fase inicial de desarrollo de la primera erupción submarina ocurrida en Canarias al no haberse dispuesto de medios de observación adecuados.

Desde las primeras imágenes de satélite que captaron la salida a la superficie del mar de las columnas de gases que teñían el agua con colores verdosos (que popularmente se conocieron como "la mancha”) se observó que la erupción tenía un carácter fisural, con varios focos alineados en la dirección del rift $\mathrm{S}$, ubicados en su área de influencia y a unos $2 \mathrm{~km}$ de distancia del puerto de La Restinga (Fig. 7).

A partir de las campañas batimétricas del B/O Ramón Margalef (nombradas como Bimbache 1011) se observó asimismo esa tendencia eruptiva fisural, si bien con el predominio de un cono princi- pal que tuvo un importante desarrollo volumétrico (Fig. 8).

En la primera campaña batimétrica del B/O Ramón Margalef (Bimbache 1011-1, 23-25 octubre 2011) se determina la ubicación precisa de ese cono principal en las coordenadas $27^{\circ} 37^{\prime} 07^{\prime}$ ' $\mathrm{N}$ y $17^{\circ}$ 59' 35" O, a unos 2,5 km al SE del terremoto con M 4,4 del 8 de octubre de 2011 (ver fig. 4A). En consecuencia, aunque el terremoto de M 4,4 pudo ser el desencadenante de la fracturación hidráulica en la base de la corteza que permitió el rápido ascenso del magma a la superficie, la fuerte anisotropía que suponen las estructuras de rift (Carracedo, 1994) obligó a este magma a surgir en el eje del rift S.

Asimismo, se obtuvieron los primeros parámetros morfométricos del cono: base de unos $650 \mathrm{~m}$ de diámetro, dos posibles cráteres y altura de unos $100 \mathrm{~m}$, lo que lo situaba a una profundidad de unos $220 \mathrm{~m}$ (ver fig. 8A). Este cono se emplazó en la cabecera de un valle submarino formado en el flanco oeste del rift $\mathrm{S}$ y cartografiado años antes de esta erupción por 


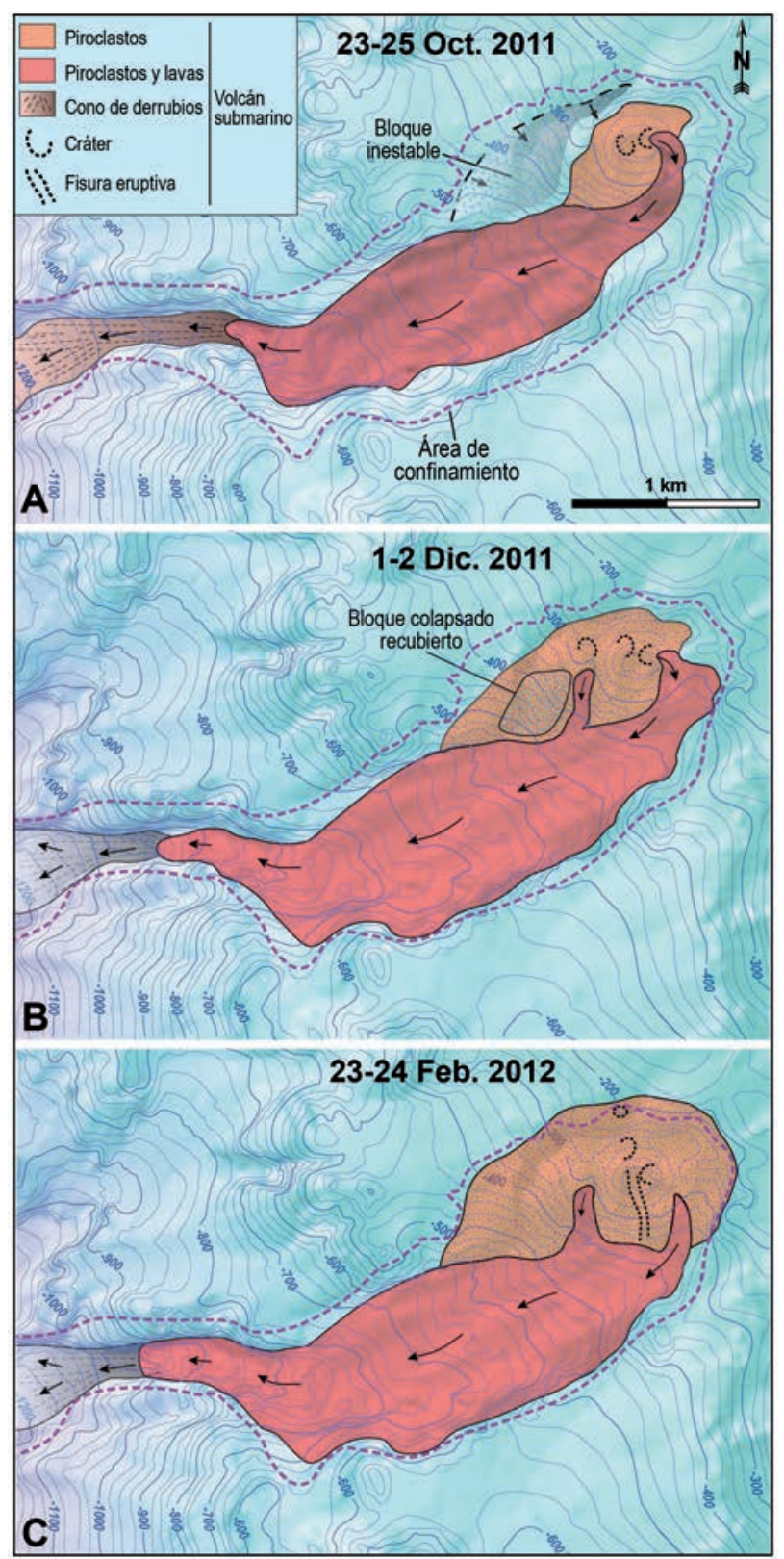

Fig. 8.-Mapas de la erupción submarina marcando su evolución morfométrica (a partir de las campañas oceanográficas llevadas a cabo por el B/O Ramón Margalef del IEO). A) Morfología y extensión de los materiales observada en la campaña Bimbache 1011-1 del 23 al 25 de octubre 2011. B) Idem para la campaña Bimbache 1011-6 del 29 de noviembre al 3 de diciembre 2011. C) Idem para la campaña Bimbache 1011-11 del 23 al 24 de febrero 2012.

el B/O Hespérides (ver figs. 2A y 2B). La profundidad previa al cono en esa cabecera del valle estaba entre los 400 a $350 \mathrm{~m}$, con un ancho medio en su fondo de unos $1000 \mathrm{~m}$ hasta alcanzar las batimétricas de 900-1000 m. A partir de esas batimétricas, el fondo del valle sufre un notable estrechamiento (se reduce a unos $500 \mathrm{~m}$ ) para posteriormente volver a expandirse en la batimétrica de 1100. La pendiente media a lo largo de todo el valle se mantiene en unos $11^{\circ}$. Este valle encauzó los materiales que surgieron del volcán y sufrieron transporte, tanto piroclastos como lavas. La posible existencia de esas lavas queda de manifiesto en la observación de las morfologías localizadas al E del cono, donde se aprecia la formación de muros laterales (levées) característicos de las coladas lávicas (ver figs. 2C y 8A).

La segunda campaña batimétrica (Bimbache 1011-2, 28-31 octubre 2011) se realizó como apoyo a las tareas de adquisición de imágenes de la erupción mediante ROV y trineo de video remolcado. Sin embargo, las difíciles condiciones ambientales que encontraron en las aguas cercanas al foco eruptivo limitaron las maniobras de ambos equipos, truncando la toma de imágenes directas de la erupción y determinando que el IEO no volviera a retomar esta tarea en los meses siguientes. En cuanto al seguimiento morfométrico del volcán, se observó que había sufrido un deslizamiento en su flanco SO, reduciendo su altura y, en consecuencia, aumentando su profundidad hasta unos $260 \mathrm{~m}$.

La formación de conos adventicios se manifiestó de forma muy clara en la tercera campaña batimétrica (Bimbache 1011-4, 12-13 noviembre 2011). Asimismo, se observó la caída de un bloque de sustrato de unos 500x300 m de tamaño desde la ladera oeste del valle, lo que evidenciaba la notable vibración a la que estaba siendo sometido el terreno en los alrededores del área eruptiva.

En la cuarta campaña batimétrica (Bimbache 1011-6, 29 noviembre-3 diciembre 2011) el cono principal creció hasta los $160 \mathrm{~m}$ de profundidad, el bloque de sustrato caído quedó cubierto por material piroclástico y se siguieron apreciando conos adventicios. El campo de lava era mucho más extenso, abarcando casi todo el ancho del fondo del valle y llegando hasta la zona de estrechamiento en las batimétricas de 900-1000 m. A partir de esas profundidades, parece que se generó una especie de cono de deyección que canalizó un importante volumen de los materiales volcánicos emitidos, sin poder precisar su posible naturaleza y extensión, ya que quedaba fuera del alcance de los ecosonar (ver fig. 8B). Coincidente con esta cuarta campaña batimétrica, otro buque oceanográfico, el Sarmiento de Gamboa (UTM-CSIC) realizó también un levantamiento batimétrico, además de llevar a cabo perfiles sísmicos de refracción y reflexión. Este buque esti- 
mó la profundidad de la cima del volcán submarino en unos $150 \mathrm{~m}$, por tanto coincidente con la indicada por el B/O Ramón Margalef.

Desde la cuarta campaña batimétrica del B/O Ramón Margalef, la erupción volcánica parecía que iba disminuyendo su actividad, según se apreciaba en la señal sísmica asociada. A pesar de ello, en la quinta campaña batimétrica (Bimbache 1011-7, 1011 enero 2012) se detectó un considerable aumento del material emitido, especialmente en el cono principal que adquirió unos $220 \mathrm{~m}$ de altura (alcanzando profundidades de unos $130 \mathrm{~m}$ ) y flancos con pendientes más pronunciadas $\left(33,6^{\circ}\right)$. Esta misma tendencia se observó en las dos siguientes campañas batimétricas (Bimbache 1011-9 y 1011-11). Por primera vez se presentaron cálculos volumétricos para el conjunto de los materiales emitidos, unos $57 \times 10^{6} \mathrm{~m}^{3}$ para lo que el IEO denominó curso alto (cono y lava hasta la batimétrica de los $950 \mathrm{~m}$ ) y unos $88 \times 10^{6} \mathrm{~m}^{3}$ para el cono de deyección (desde la batimétrica de $950 \mathrm{~m}$ hasta la de $2000 \mathrm{~m}$ ). El volumen calculado para el cono y campo de lava es de un orden de magnitud similar al calculado para algunas erupciones holocenas subaéreas de la isla, como por ejemplo la del volcán Montaña del Tesoro cuyo campo de lava formó la plataforma de Tamaduste al NE (Rodriguez-Gonzalez et al., 2011). Sin embargo, la suma de los volúmenes del curso alto y cono de deyección $\left(145 \times 10^{6} \mathrm{~m}^{3}\right)$ supera en al menos dos órdenes de magnitud a todas las erupciones holocenas subáreas calculadas. Dada la incertidumbre en los análisis morfométricos para las grandes profundidades (que incluye todo ese cono de deyección), es posible que este volumen haya sido sobrestimado.

En la sexta campaña batimétrica (Bimbache 1011-9, 7-8 febrero 2012) se determinó que la altura del cono principal había crecido hasta los $230 \mathrm{~m}$ (situándolo a profundidades de unos $120 \mathrm{~m}$ ) y la pendiente de sus flancos había aumentado hasta los $35^{\circ}$. Asimismo, era perceptible el crecimiento de un cono adventicio al SE del principal.

La séptima y última campaña batimétrica realizada hasta la fecha por el B/O Ramón Margalef (Bimbache 1011-11, 23-24 febrero 2012) coincidió con un periodo donde la señal del tremor presentaba una amplitud muy baja (ver fig. 6B). A pesar de ello se detectó un nuevo aumento significativo en el volumen del cono, cuya cima ya alcanzaba los $88 \mathrm{~m}$ de profundidad. Asimismo, se apreció un aumento significativo de la superficie cubierta por el cono, que rebasó la cabecera del valle, y por el campo de lava,
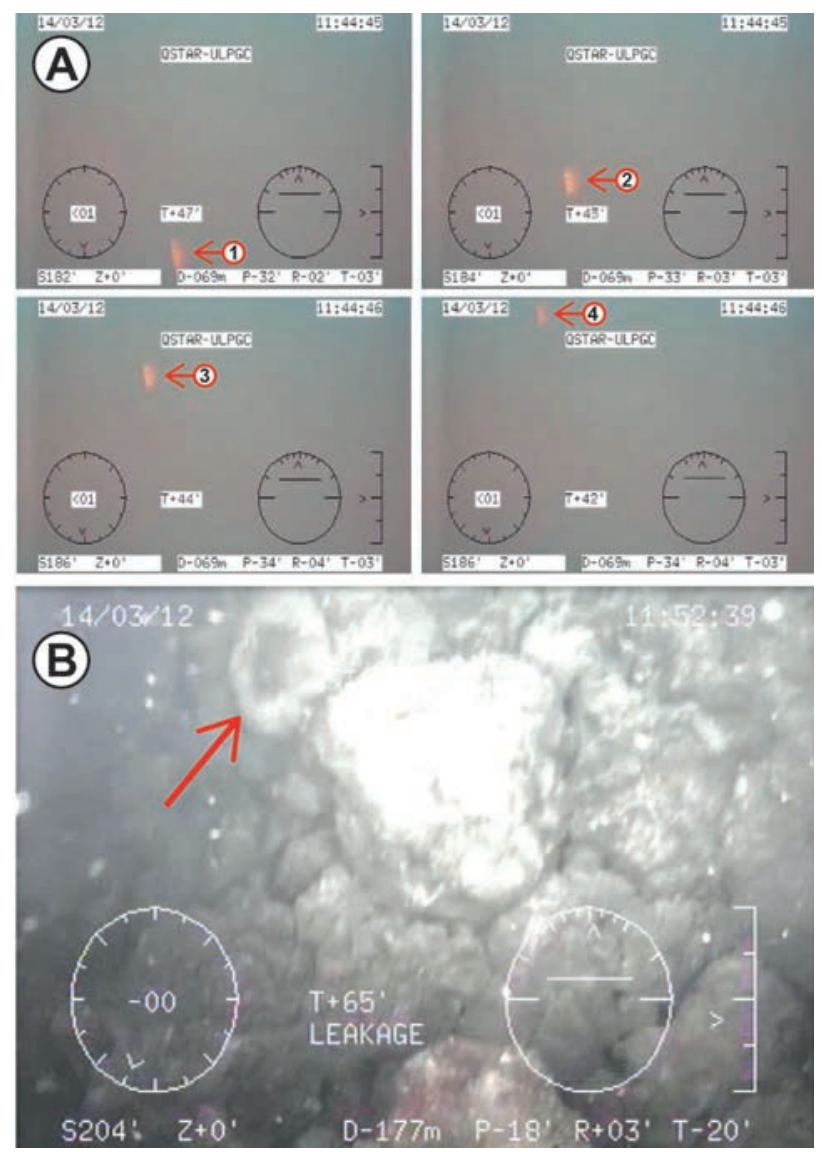

Fig. 9.-Primeras imágenes que se obtuvieron del volcán en la campaña Guayota-2 de la ULPGC del 13 al 14 de marzo 2012. A) Posible piroclasto incandescente muy cerca de la boca eruptiva. Obsérvese como el color rojo se mantiene a todo lo largo de la pantalla, imposibilitando que sea un reflejo de los focos del ROV que, dada la inclinación de la cámara, ilumina directamente su mitad inferior. Estas imágenes se tomaron a una profundidad de $69 \mathrm{~m}$, muy cerca de la boca eruptiva (estimada a unos 86-88 m de profundidad) y la sucesión de las 4 imágenes que marca el vuelo ascendente del piroclasto dura apenas un segundo. B) Ladera SO del cono principal a la profundidad de $177 \mathrm{~m}$. La flecha marca la existencia de lava balloons formando parte del mismo.

aunque éste último siguió confinado en el valle. Un rasgo notable también detectado fue la existencia de una especie de cresta de unos $675 \mathrm{~m}$ de longitud en la dirección $\mathrm{N} 154^{\circ} \mathrm{E}$ al SE del cráter del cono principal, evidencia inequívoca de erupción fisural controlada por la directriz estructural impuesta por el rift S (ver fig. 8C).

La Universidad de Las Palmas de Gran Canaria (ULPGC) comenzó en febrero de 2012 una serie de campañas oceanográficas (denominadas Guayota) para el estudio integral de esta erupción submarina y su repercusión en el entorno marino. Para ello contrató los servicios del B/O Atlantic Explorer de 
la empresa QSTAR que cuenta con un robot submarino (ROV) dotado de una cámara de vídeo. En la campaña Guayota-2 (13-14 marzo 2012) se sumergió este ROV en áreas próximas a la cima del volcán, pudiéndose filmar el mismo por primera vez. Se corroboró que esa cima se encontraba a unos 88 $\mathrm{m}$ de profundidad, que sus flancos presentaban pendientes muy pronunciadas y que la actividad volcánica era ya prácticamente residual, con escasa emisión de piroclastos (Fig. 9A). Asimismo, al menos en lo que respecta al flanco SO, se observó que estaba formado por la acumulación de material escoriáceo de gran tamaño que, en numerosas ocasiones, presentaba interiores huecos (Fig. 9B), similares a las lava balloons que alcanzaron la superficie del mar a partir del mes de noviembre de 2011 y que serán tratadas en el siguiente apartado.

\section{Materiales volcánicos flotantes}

La constancia real de una erupción volcánica submarina (y no simplemente de una manifestación de carácter hidrotermal) en El Hierro llegó el 15 de octubre de 2011 con la llegada a la superficie del mar de bombas y escorias volcánicas juveniles de 10 a $40 \mathrm{~cm}$ de diámetro. Estas bombas flotantes, rápidamente bautizadas como "restingolitas", eran muy similares a las emitidas en erupciones basálticas fisurales de carácter estromboliano (p. ej., en la erupción del Teneguía en La Palma en 1971). Sin embargo, el hecho más llamativo era el material blanco y muy poroso que formaba el interior de las bombas, interdigitado y recubierto de una fina capa de material basanítico vítreo negro (Fig. 10A). Esta característica textural no había sido observada en erupciones anteriores, por lo que el análisis de su naturaleza y origen ha sido objeto de numerosas interpretaciones. Gimeno (2011) aportó los primeros datos químicos de ambos materiales, llegando a la conclusión de que el borde externo negro estaría formado a partir de un magma basanítico, mientras que el interior blanco sería una riolita alcalina, con evidencias texturales de mezcla de magmas entre ambos materiales. Por otro lado, los representantes del CSIC que formaban parte del comité científico del Plan Especial de Protección Civil y Atención de Emergencias por Riesgo Volcánico en la Comunidad Autónoma de Canarias (PEVOLCA) concluyeron que "los fragmentos están formados por una mezcla entre dos materiales magmáticos, uno negro (basalto) y otro blanco (traquita), que se produjo en el momento de la erupción, por lo que se trata de una mezcla física entre ambos materiales sin que entre los dos haya habido reacción química" (Gobierno de Canarias, 2011. Comunicado de prensa del 2 de noviembre 2011). Ambas interpretaciones, particularmente la primera, suponían un importante incremento del riesgo eruptivo, ya que la posible existencia de magmas sálicos significaría "un potencial explosivo grande" (Gimeno, 2011). En una interpretación diferente, el vidrio blanco micro-vesiculado se asoció a "una perlita expandida" (Coello, 2011), formada a partir de la hidratación de una capa de hialoclastitas de una erupción submarina anterior. Finalmente, Troll et al. (2012) realizaron un estudio detallado del material poroso blanco para el que acuñaron el término de "xenolitos pumíticos" (xenopumice), considerándolos como inyecciones de los sedimentos oceánicos pre-volcánicos parcialmente fundidos y vesiculados englobados por el magma basanítico ascendente.

Con el trascurso de la erupción las bombas con núcleo blanco poroso ("restingolitas") desaparecieron, siendo sustituidas por otras bombas huecas con una delgada corteza vítrea negra con tamaños entre 30 y $200 \mathrm{~cm}$ (Fig. 10C y D). Una vez alcanzada la superficie del mar, este material se fragmentaba rápidamente, debido a su enfriamiento y consiguiente pérdida de volumen, desgasificándose y permitiendo la entrada de agua marina en su interior. De este modo, perdían su flotabilidad inicial y se hundían en poco tiempo, dificultando enormemente su recogida de forma que las primeras muestras se consiguieron el 27 de noviembre de 2011. La formación de estas bombas volcánicas huecas había sido documentada en varias erupciones submarinas, como la de Loihi, en Hawaii (Clague et al., 2000), o La Serreta, en Terceira, Azores (Forjaz et al., 2000; Gaspar et al., 2003). Es precisamente en esta erupción de La Serreta (1998-2001), formada a profundidades entre 300 a $1000 \mathrm{~m}$, donde se formuló un modelo genético para este material volcánico flotante y se propuso un término propio: lava balloons (Forjaz et al., 2000; Gaspar et al., 2003). Según este modelo, las lava balloons serían una especie de pillow-lavas expulsadas hacia la superficie cerca de la boca de salida en los típicos pulsos estrombolianos de fuente de lava (lava fountaing). Alto contenido en volátiles y baja viscosidad del magma (magmas alcalinos) son los factores principales que permiten su generación (Gaspar et al., 2003; Kueppers et al., 2012). Asimismo, su formación suponía un estilo eruptivo propio (que 

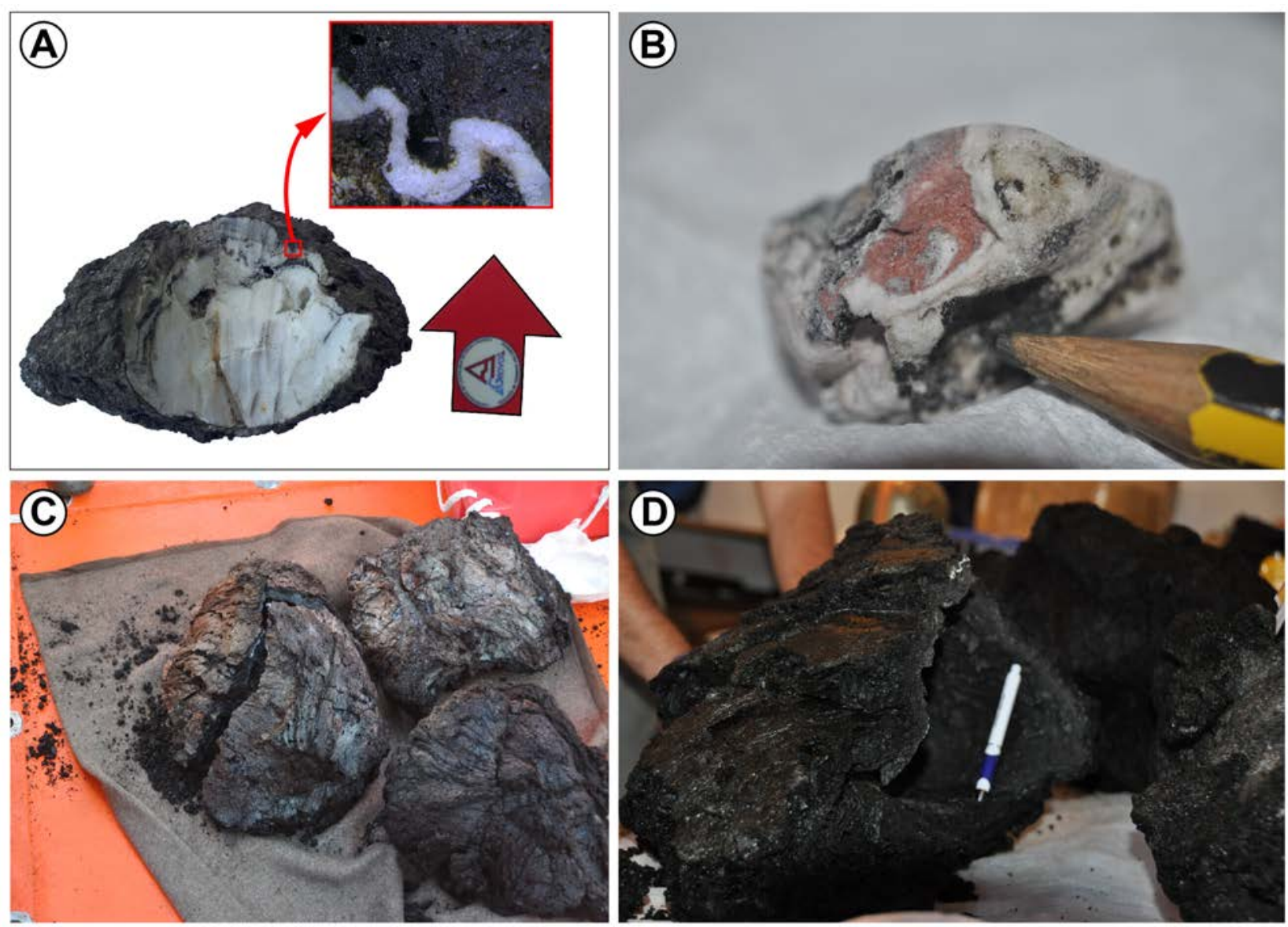

Fig. 10.--Material volcánico que alcanzó la superficie del mar a lo largo de la erupción. A) Bombas con núcleo poroso blanco (bautizadas como "restingolitas") muy frecuentes en la primera semana de la erupción. En el recuadro se marca un detalle de las texturas de mezcla entre ese material blanco y el borde negro basanítico. B) Fragmento de "restingolita" en el que se aprecia la existencia de jaspe. C y D) Con el progreso de la erupción las bombas pasaron a ser huecas (lava balloons), alcanzando volúmenes de hasta $1 \mathrm{~m}^{3}$ (primeras muestras recogidas el 27 de noviembre 2011)

denominaron como serretyan eruption) dentro de las erupciones submarinas, que sería una variante más profunda y menos explosiva que el surtseyano (Forjaz et al., 2000).

\section{Análisis de la naturaleza y origen de las bombas flotantes de núcleo poroso blanco ("restingolitas")}

La observación previa de xenolitos similares en La Palma (Klugel et al., 1999), en el volcán submarino Hijo de Tenerife, entre Tenerife y Gran Canaria (Schmincke \& Graf, 2000), en Gran Canaria (Hansteen \& Troll, 2003), Lanzarote (Aparicio et al., 2006, 2010) y Fuerteventura (Stillman et al., 1975), pone de manifiesto que las "restingolitas" no son tan exclusivas de la erupción submarina de El Hie- rro. En particular, xenolitos de arenisca vesicular de Gran Canaria son sorprendentemente parecidos a las "restingolitas" en textura, composición y aspecto general (Troll et al., 2012).

Aunque la composición pueda parecer a primera vista la de una riolita o traquita, ya que como tales se proyectan en un diagrama TAS (Tabla 1 y Fig. 11A), esto no es en absoluto suficiente para determinar que se trate de un magma juvenil, pudiendo tratarse de un magma anatéctico proveniente de la fusión parcial de sedimentos ricos en sílice o de los propios sedimentos que se proyectarían en el mismo campo. Sin embargo, el contenido mineralógico (Fig. 11B) y en elementos traza difieren de una riolita o traquita producidas por diferenciación magmática de un magma mantélico básico (Troll et al., 2012). Asimismo, en algunas muestras pueden observarse a simple vista fragmentos de jaspe (ver 
Tabla 1.-Análisis de elementos mayoritarios (\%, $\mathrm{m} / \mathrm{m}$ ) de los núcleos blancos de las "restingolitas" (tomado de Troll et al., 2012) y de una lava balloon (muestra EH-BASAN) recogida el 27 de noviembre de 2011 (realizado mediante espectrometría de fluorescencia de rayos $X$ en la Universidad de Bonn, Alemania, por K. Pedroza y R. Hoffbauer)

\begin{tabular}{lrrrr}
\hline Muestra & H12110 & EH2510-1 & EH2110-2 & EH BASAN \\
\hline $\mathrm{SiO} 2$ & 69,19 & 71,03 & 68,00 & 42,36 \\
$\mathrm{TiO} 2$ & 0,22 & 0,18 & 0,21 & 4,75 \\
$\mathrm{~A} 2 \mathrm{O} 3$ & 15,76 & 15,10 & 15,43 & 13,39 \\
$\mathrm{Fe} 2 \mathrm{O} 3$ & 0,73 & 0,69 & 0,71 & 14,73 \\
$\mathrm{MnO}$ & 0,01 & 0,02 & 0,02 & 0,19 \\
$\mathrm{MgO}$ & 0,31 & 0,12 & 0,55 & 7,36 \\
$\mathrm{CaO}$ & 0,48 & 0,31 & 0,47 & 10,64 \\
$\mathrm{Na} 2 \mathrm{O}$ & 6,09 & 6,11 & 6,52 & 3,75 \\
$\mathrm{~K} 2 \mathrm{O}$ & 4,88 & 4,73 & 4,78 & 1,46 \\
$\mathrm{P} 2 \mathrm{O} 5$ & 0,07 & 0,04 & 0,05 & 0,83 \\
LOI & 1,19 & 1,06 & 1,00 & $-0,79$ \\
Total & 98,93 & 99,39 & 98,35 & 99,46 \\
\hline
\end{tabular}

fig. 10B), agregados de yeso, carbonatos y algunos cristales de cuarzo. Esta aparición de cristales de cuarzo es un factor determinante respecto a su origen, ya que el cuarzo libre es incompatible con el volcanismo de las Islas Canarias y ha de proceder del continente africano.

En consecuencia, el origen de las "restingolitas" es un apasionante debate petrológico aún abierto, donde estudios más precisos (p. ej., isótopos discriminadores, inclusiones fluidas y vítreas, etc.) podrán precisar con mayor exactitud su génesis.

No obstante, la propia dinámica de la erupción, donde no ha habido constancia de pulsos eruptivos de alta explosividad, restricción de las "restingolitas" a los primeros días de la erupción, así como la morfología de los conos cartografiados, parecen apuntar hacia erupciones submarinas poco explosivas (tipo serretianas), por tanto sin intervención, al menos volumétricamente importante, de magmas sálicos que conferirían un grado de explosividad mayor.

Por tanto, el modelo de una fusión parcial de sedimentos pre-volcánicos que, dado su contraste de temperatura y viscosidad, sólo se mezclarían físicamente (mingling) con el magma basanítico proveniente del manto cobra más fuerza. El proceso de formación según este modelo se indica en el esquema de la figura 12. El magma mantélico en su ascenso a través de la corteza oceánica funde parcialmente (anatexia) depósitos ricos en sílice que forman parte de la capa 1 de la corteza oceánica. El

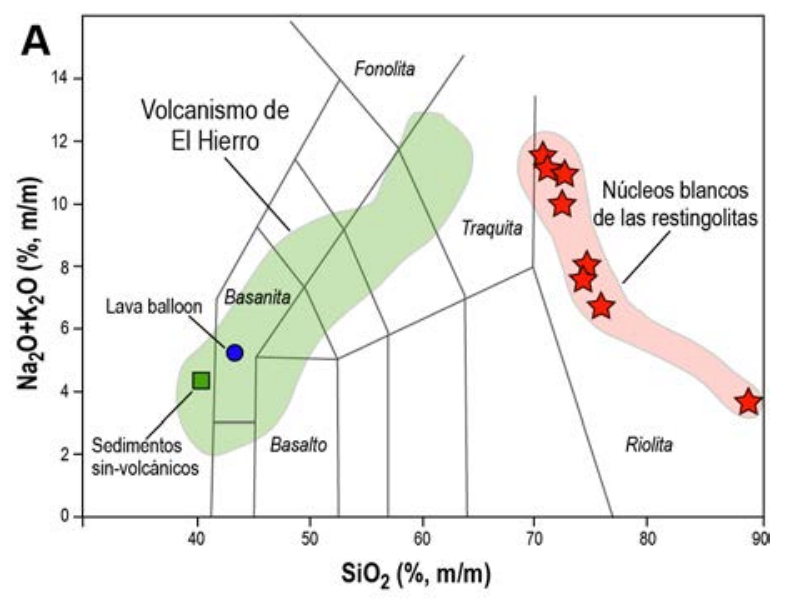

B

\begin{tabular}{|llllllllll|}
\hline MUESTRA olivino & piroxeno anfibol feldespato & mica & cuarzo & illita & halita esmectita \\
\hline EH-XP-1 & 0 & 0 & 0 & 0 & 0 & 0 & 0 & 0 & 0 \\
EH-XP-2 & 0 & 0 & 0 & 0 & 0 & 0 & 0 & 0 & 0 \\
EH-XP-3 & 0 & 0 & 0 & 0 & 0 & 0 & 0 & 0 & 0 \\
\hline
\end{tabular}

Fig. 11.-A) Proyección de las composiciones de una muestra de lava balloon y de varios núcleos blancos porosos de las "restingolitas" que aparecen en la tabla 1 en un diagrama TAS $\left(\mathrm{SiO}_{2}\right.$ vs. álcalis). Aunque la proyección de esos núcleos blancos de las "restingolitas" cae en el campo de las riolitas-traquitas, se trata de un fundido parcial de sedimentos prevolcánicos de la capa 1 de la corteza oceánica. Los sedimentos del flanco de la isla presentan, en cambio, un comportamiento acorde con su origen volcánico (modificado de Troll et al., 2012). B) Minerales presentes en los núcleos blancos porosos de las "restingolitas". Obsérvese la ausencia de los minerales típicos de las rocas volcánicas y la presencia de cuarzo y arcillas.

cuarzo de estos sedimentos es de origen detrítico, proveniente del continente africano, bien en forma de polvo en suspensión (las fracciones más finas), bien en corrientes de turbidez (Gee et al., 1999; Ye et al., 1999; Krastel \& Schmincke, 2002; Criado \& Dorta, 2003).

La presencia de fases minerales características de ambientes sedimentarios, así como la ausencia de fases minerales típicas magmáticas en los núcleos blancos de las "restingolitas" (ver fig. 11B), indican que éstas no se derivan de un magma juvenil diferenciado ni de la fusión parcial de sedimentos de los flancos de la isla, en cuyo caso deberían aparecer minerales típicos de las rocas volcánicas canarias (como olivinos, clinopiroxenos, anfíboles o feldespatos). Los sedimentos pre-volcánicos que constituyen la capa 1 de la corteza oceánica cumplen este requisito, ya que hay que recordar que la corteza bajo las Canarias Occidentales es de edad Jurásica, muy anterior a la formación del archipiélago (en 
realidad a todo el volcanismo macaronésico) y, por tanto, ajenos a la influencia de sus materiales volcánicos.

Por otro lado, las texturas de interacción núcleos blancos-magma basanítico parecen indicar que los sedimentos estuvieron poco tiempo (posiblemente solo horas) en contacto con el magma antes de la erupción, mientras que la asimilación completa e hibridación hubiera requerido más tiempo (McLeod \& Sparks, 1998; Perugini et al., 2010).

La fusión parcial del sedimento y su vesiculación conllevaron una acusada disminución de su densidad, aumentando su flotabilidad tanto en el magma como en el agua del mar. Paralelamente, la progresiva desgasificación aumentaría la temperatura de fusión del sedimento, que solidificaría, facilitando así su desprendimiento de la lava y su ascenso como "bombas flotantes" en la fase temprana de la erupción, cuando el magma tuvo que abrir y consolidar un conducto eruptivo a través de los sedimentos. Esto explicaría que el aporte de "restingolitas" cesara al avanzar la erupción, una vez el conducto se aisló del contacto con la capa sedimentaria, y fueran sustituidas por lava balloons, ya enteramente magmáticas y de la misma composición basanítica que el borde negro externo de las "restingolitas" (ver tabla 1 y fig. 11A).

\section{Gestión de la crisis}

Esta erupción submarina de El Hierro ha supuesto la primera oportunidad en 40 años en Canarias de gestionar una crisis de estas características. Se ha progresado considerablemente desde la anterior erupción del Teneguía en La Palma en 1971, en la que no se disponía de instrumentación adecuada para registrar la sismicidad o deformaciones del terreno. La disponibilidad de dos estaciones sísmicas en El Hierro con anterioridad a la crisis (ver fig. 3) permitió su detección temprana y el despliegue de más medios hasta completar una red multiparamétrica para el seguimiento de la actividad precursora y acompañante de la erupción. Sin embargo podría preguntarse si ha sido correlativa la eficacia en la gestión de esta crisis a la disponibilidad de más y mejores medios técnicos y científicos. Conviene intentar contestar a esta cuestión, analizando las observaciones e interpretaciones obtenidas y las decisiones adoptadas, para profundizar en la mejora de la gestión de futuras crisis similares.

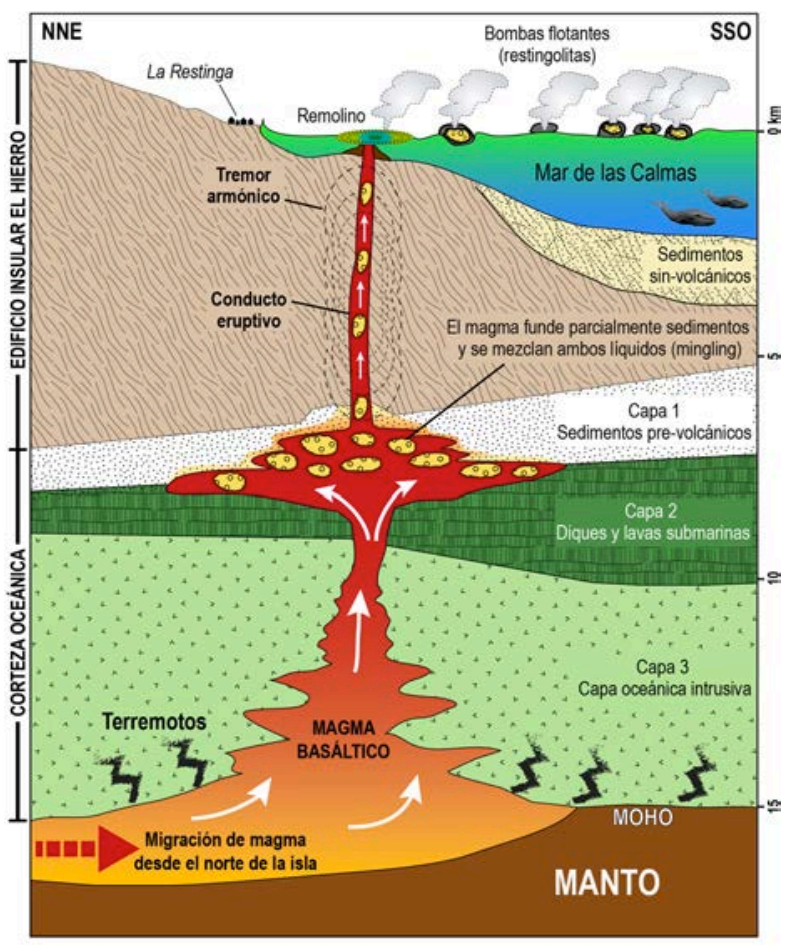

Fig. 12.-Esquema ilustrativo del posible origen de las "restingolitas". El magma que, de acuerdo con la distribución de la sismicidad anterior a la erupción, se desplazó de $\mathrm{N}$ a $\mathrm{S}$ en la corteza oceánica interaccionó con los sedimentos oceánicos prevolcánicos, fundiéndolos parcialmente (anatexia) y vesiculándolos, de modo que se genera un líquido ácido que se mezcla físicamente (mingling) con el magma basanítico (modificado de Troll et al., 2012).

\section{Contexto de la gestión}

El seguimiento de la actividad precursora y acompañante de una erupción conlleva una amplia y variada instrumentación y metodologías, entre las que destacan las sísmicas, geodésicas y geoquímica de gases (e.g., McNutt et al., 2000; Tilling, 2008; Donovan et al., 2012). Ahora bien, para la correcta implementación de las redes instrumentales y la adecuada interpretación de sus datos es necesario el conocimiento geológico detallado del área volcánica a monitorear (e.g. Tilling, 2008). Asimismo, a lo largo de una crisis volcánica es conveniente aglutinar a todos los científicos especialistas que puedan aportar datos relevantes que ayuden a la comprensión del evento y, por consiguiente, a su mejor gestión (Tilling, 2008; Donovan \& Oppenheimer, 2012). Por otro lado, aunque durante una crisis volcánica los mayores esfuerzos deben encaminarse hacia su vigilancia y gestión, ello no debe ser obstáculo para la investigación de todos sus paráme- 
tros, ya que una erupción volcánica supone el mejor laboratorio natural y la mejor oportunidad para la comprensión de este fenómeno y, en consecuencia, para el avance de la volcanología (Geist \& Garcia, 2000).

En el año 2004 se aprobó el Real Decreto $1476 / 2004$ en el que se encomienda al IGN la "observación, vigilancia y comunicación de la actividad volcánica en el territorio nacional y determinación de los riesgos asociados". Posteriormente, en el año 2010 el Gobierno de Canarias publica un decreto (73/2010) por el que se establece el Plan Especial de Protección Civil y Atención de Emergencias por Riesgo Volcánico en la Comunidad Autónoma de Canarias (PEVOLCA). Este Plan regula las actuaciones de las diferentes administraciones ante una erupción volcánica en el archipiélago, contemplando, entre los comités asesores, el Científico de Evaluación y Seguimiento de Fenómenos Volcánicos (CECES). La composición de este comité viene asimismo regulada en el decreto, que estipula que esté formado, por parte de la Administración General del Estado "por la Dirección General del IGN, el CSIC (Estación Volcanológica de Canarias e investigadores del campo de la volcanología en Canarias), la AEMET (Agencia Estatal de Meteorología) y la Dirección General de Protección Civil" y por parte de la Comunidad Autónoma de Canarias "por el ITER (Instituto Tecnológico y de Energías Renovables) y las dos Universidades Canarias".

Así pues, con anterioridad a la erupción submarina de El Hierro se cuenta con un marco normativo que regula las actuaciones en caso de crisis volcánica, el organismo encargado de su vigilancia (IGN) y las instituciones que deben actuar en el asesoramiento científico. Sin embargo, una vez iniciada la crisis sísmica precursora a mediados de julio de 2011, la composición del CECES se limita a personal del IGN, AEMET y CSIC (Instituto de Geociencias de Madrid e Instituto de Ciencias de la Tierra Jaume Almera de Barcelona), figurando además como organismo invitado el ITER (Gobierno de Canarias, 2011. Comunicados de prensa de 22 y 29 de julio 2011). Se excluye, por tanto, la participación de científicos de las dos universidades canarias (ULL -Universidad de La Laguna - y ULPGC) y de la Estación Volcanológica de Canarias (IPNACSIC, Tenerife), a pesar de que cuentan con una dilatada experiencia sobre la geología y volcanología del Archipiélago Canario, en general, y de la isla de El Hierro, en particular.

\section{Análisis del seguimiento técnico y científico de la sismicidad y deformación}

La gestión técnica de la sismicidad y deformación del terreno por parte del IGN ha demostrado que se dispone de una infraestructura técnica y humana adecuada para detectar y prevenir erupciones futuras en Canarias. Asimismo, es destacable el hecho de que el IGN presentara información en internet (http://www.ign.es/ign/resources/volcanologia/InfoHierro/HIERRO.html) y en tiempo prácticamente real sobre sismicidad, energía acumulada, deformaciones y tremor armónico (Fig. 13). En las fases finales llegó a disponerse incluso de dos webcams que proporcionaron una vista continua y en tiempo real del mar en la zona de la erupción submarina. Por último, el registro del tremor armónico ha sido especialmente útil ya que ha dado, por primera vez en Canarias, información registrada del inicio, evolución y final de una erupción.

Aunque el seguimiento técnico de la sismicidad y deformación por parte del IGN fue aceptable, no lo han sido en igual medida las interpretaciones derivadas de esa información. Así, se explicó la distribución de epicentros asociándolos a una supuesta falla N-S que dividiría la isla en dos bloques con movimientos diferenciales. Aunque la distribución de los hipocentros no apoyaba esta explicación, al no existir una dispersión vertical de los focos como podría esperarse en una falla de estas características, la postulación de tal falla y su potencial de generar sismos de magnitud considerable, motivó en diversas ocasiones el cierre del Túnel de Los Roquillos (Gobierno de Canarias, 2011. Comunicados de prensa de 27 septiembre y 4 noviembre 2011), infraestructura esencial para la isla por unir las dos zonas más pobladas (Valverde y Frontera) (Fig. 14).

\section{Análisis del seguimiento de la erupción volcánica}

Como se verá a continuación, en el seguimiento de la erupción fue donde se dieron las mayores deficiencias, lo que propició la toma de decisiones de protección civil posiblemente innecesarias (ver fig. 14).

La progresiva migración de los epicentros hacia el océano al sur de la isla, evidenciaba que de producirse una erupción sería con muy alta probabilidad submarina. Sin embargo, no se procedió a recabar la presencia de un buque oceanográfico, impres- 

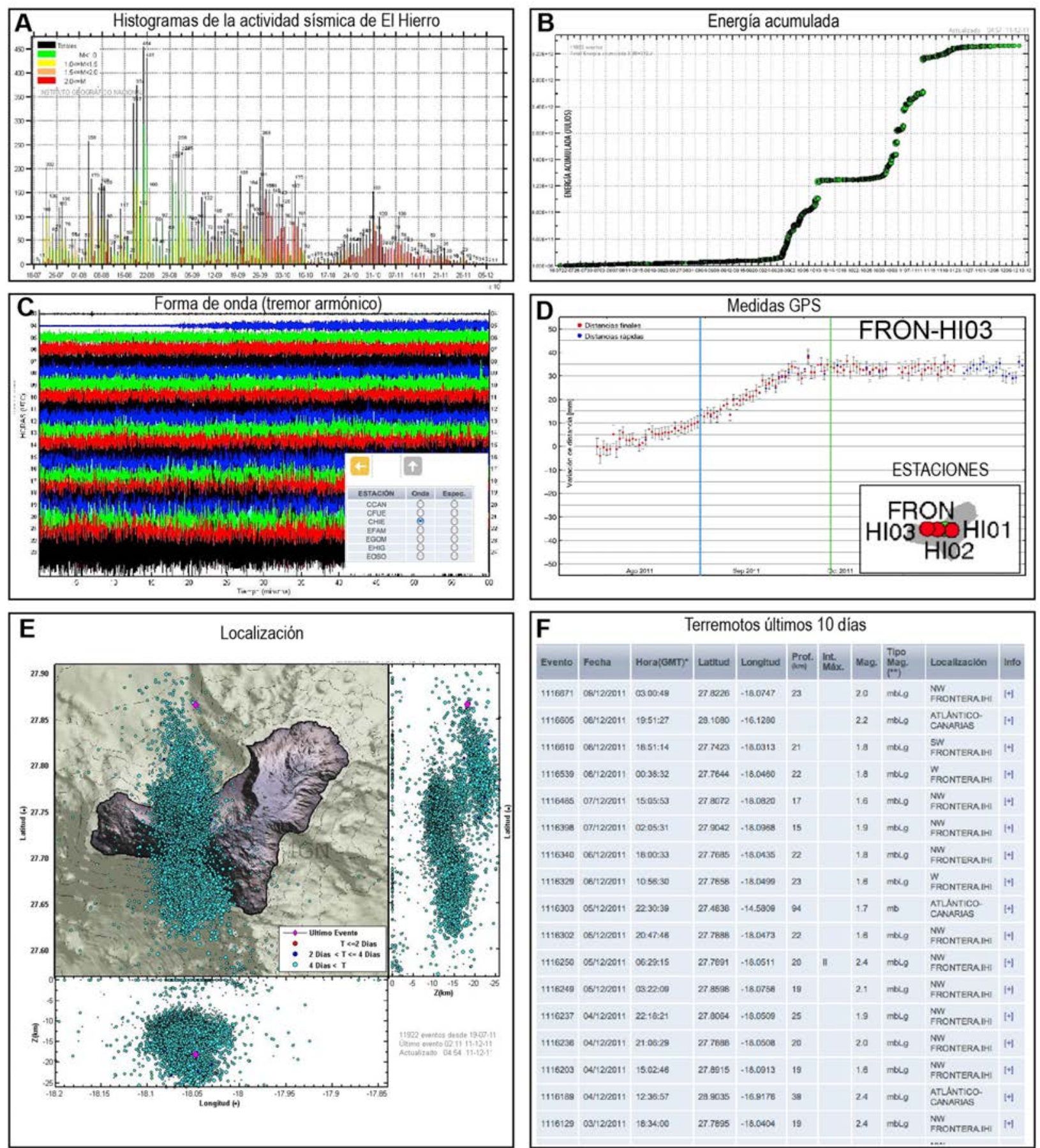

Fig. 13.-Ejemplos de la información de la erupción de 2011-12 en El Hierro proporcionada por el IGN en tiempo prácticamente real a través de Internet (http://www.ign.es/ign/resources/volcanologia/HIERRO.html). 


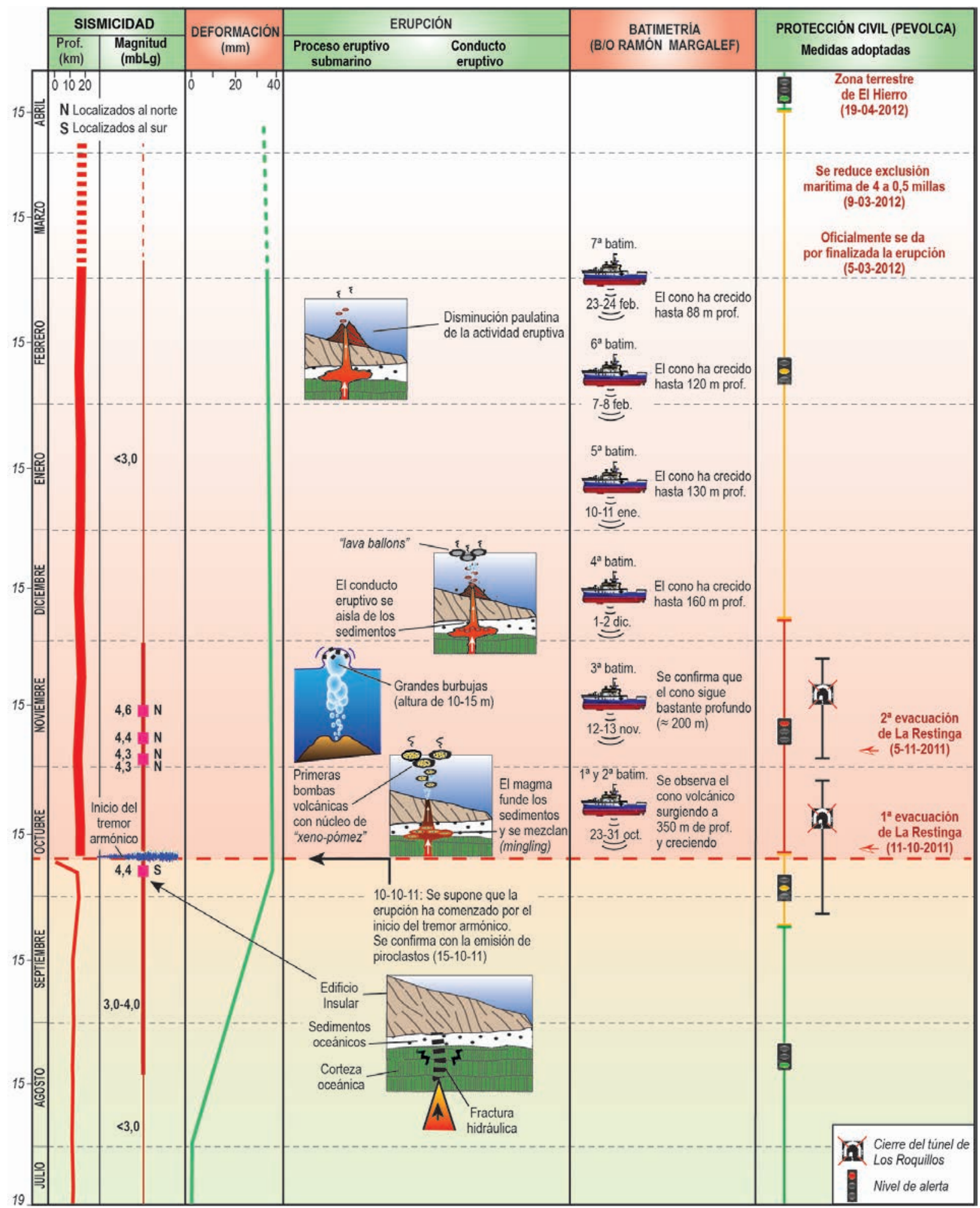

Fig. 14.-Evolución de la sismicidad y deformación del terreno (con datos del IGN), así como de los principales eventos del proceso eruptivo. Se indican, asimismo, la distribución temporal de las campañas batimétricas llevadas a cabo por el B/O Ramón Margalef (IEO) y las medidas de protección adoptadas por el PEVOLCA. 
cindible para la observación de un proceso eruptivo submarino. Aún más, el CECES consideró que "el barco sería una ayuda adicional, pero no imprescindible" (Marín, 2011). Solamente con la erupción ya en marcha y con las enormes incertidumbres que se crearon en su localización (se barajaban distancias a la costa de uno a varios $\mathrm{km}$ y profundidades desde $>1000 \mathrm{~m}$ a $<150 \mathrm{~m}$ ), se solicitó formalmente este barco (Gobierno de Canarias, 2011. Comunicados de prensa de 12 DE octubre 2011). La primera evacuación de La Restinga (547 habitantes) y la elevación al color rojo del semáforo de alerta volcánica para toda la isla (Gobierno de Canarias, 2011. Comunicados de prensa a lo largo del día 11 octubre 2011) (ver fig. 14), medidas con un alto coste humano y económico, no habrían sido necesarias de haberse contado con el buque oceanográfico, ya que, como ha quedado demostrado en el apartado de evolución morfométrica del área eruptiva, el crecimiento del cono volcánico principal no superó la batimétrica de los $100 \mathrm{~m}$ (salvo a finales de febrero 2012, pero en ese tiempo la actividad volcánica presentaba un carácter residual). Esta profundidad de $100 \mathrm{~m}$ marca el límite por debajo del cual una erupción submarina de magma básico carece de peligrosidad (e.g., Schmincke, 2004), ya que, en general, la expansión volumétrica de las moléculas de agua en fase vapor (que produciría una sobrepresión en el seno del magma capaz de fragmentarlo y provocar una erupción explosiva) es muy baja (Fig. 15).

Por otro lado, las continuas especulaciones en el ámbito del CECES sobre presencia de magma diferenciado (traquítico) y mecanismos eruptivos surtseyanos de alta explosividad (Gobierno de Canarias, 2011. Comunicados de prensa de 15 de octubre y 2 de noviembre de 2011) aumentaron el nivel de alarma y la fuga de visitantes. Este preocupante escenario eruptivo, ampliamente recogidos en los medios de comunicación, cesó cuando el B/O Ramón Margalef (IEO) realizó la primera campaña batimétrica (23-25 de octubre de 2011), localizando el cono volcánico a unos $350 \mathrm{~m}$ de profundidad y con su cima en la batimétrica de los $220 \mathrm{~m}$ (ver figs. 2B, 2C y 8A)). Asimismo, la explicación para los núcleos blancos de las "restingolitas" como sedimentos parcialmente fundidos y vesiculados (Troll et al., 2012), sugería un proceso eruptivo poco explosivo que, por otra parte, es el más común en el volcanismo holoceno de El Hierro (Carracedo et al., 2001).

Sin embargo, ante la aparición el 5 de noviembre de 2011 de numerosas zonas de burbujeo en la

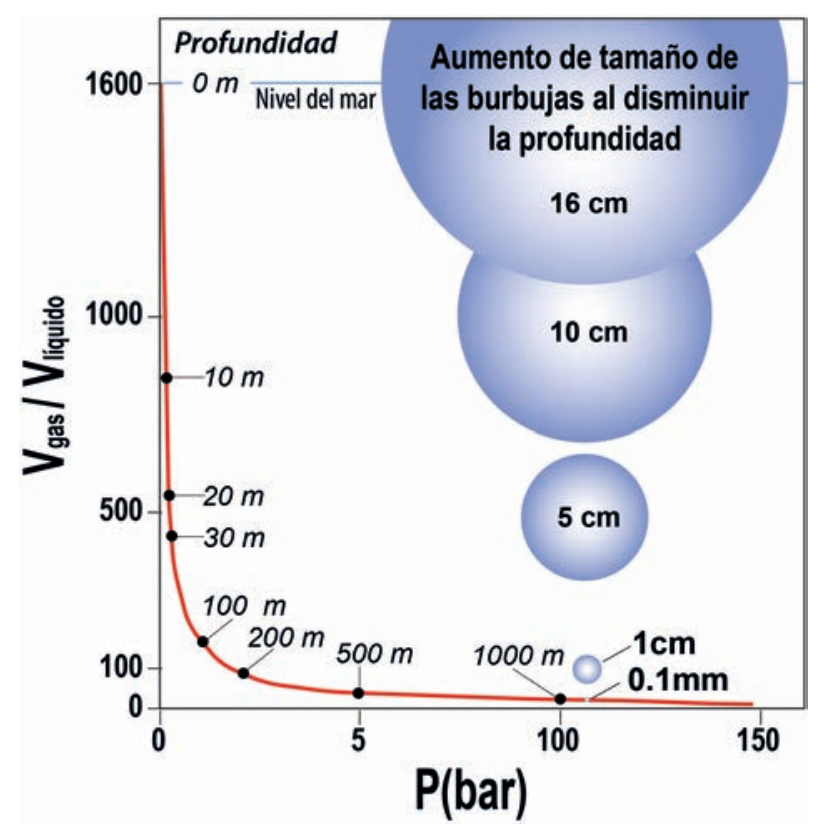

Fig. 15.-Gráfico donde se muestra la presión de la columna de agua de mar (equivalente a la profundidad) versus la relación del volumen de la molécula de agua en fase líquida y fase vapor. Se observa cómo a partir de la profundidad de 100 m esa relación volumétrica se dispara exponencialmente (modificado de Schmincke, 2004). Este es el origen de la elevada explosividad de las erupciones submarinas someras (surtseyanas) de magmas básicos.

superficie del mar claramente alineadas, probablemente en relación con explosiones rítmicas de la erupción submarina, algunas de las cuales alcanzaron una extensión y altura considerables (hasta 20 $\mathrm{m}$ de altura), se vuelve al modelo explosivo surtseyano para su interpretación. Ello indujo a las autoridades a realizar una segunda evacuación de La Restinga ese mismo día (Nota de prensa del Gobierno de Canarias con fecha 5 de noviembre 2011) (ver fig. 14), con el consiguiente desconcierto entre la población afectada. Hay que destacar que durante la erupción de La Serreta, Azores (1998-2001), con la que la erupción submarina de El Hierro de 2011-12 tiene muchos paralelismos, como se ha puesto de manifiesto en apartados anteriores, se observaron en varias ocasiones formación de burbujas similares con alturas de hasta $30 \mathrm{~m}$ (Forjaz et al., 2000). Por otro lado, los datos batimétricos obtenidos en la campaña oceanográfica Bimbache 1011-2, finalizada el 31 de octubre 2011, seguían indicando que la cima del cono se encontraba muy profunda (a unos 200 m). Asimismo, según consta en el informe de la campaña oceanográfica Bimbache 1011-6 del IEO, 
personal científico de este instituto mantiene informado al PEVOLCA en reuniones periódicas, algunas de ellas con fecha de 4 y 5 de noviembre 2011. Así pues, si se conocía la experiencia previa eruptiva de La Serreta, donde no hubo evidencias de mecanismos surtseyanos, y el IEO aseguraba que el 31 de octubre de 2011 el volcán aún estaba muy profundo, por tanto sin riesgo de mecanismos explosivos, ¿por qué se inicia esta segunda evacuación?. Parece obvio que, tanto en el seno del CECES como del PEVOLCA, se guiaron por el principio de que en caso de incertidumbre científica ante el evento vigilado debe primarse la seguridad (de las personas, política, económica, etc.), lo que casi irremediablemente concluye en evacuaciones (Donovan \& Oppenheimer, 2012). Esta actuación induce a formular nuevas preguntas: ¿qué hubiera pasado si la composición del CECES no hubiera sido tan restrictiva? ¿se hubiera rebajado el nivel de incertidumbre?

Un último aspecto a valorar es que, si bien el IGN siguió registrando en continuo las $24 \mathrm{~h}$ del día, tanto la sismicidad como las deformaciones asociadas al evento eruptivo, otros dos parámetros imprescindibles para su correcta vigilancia e interpretación, como son la evolución geoquímica-petrológica del magma a través de sus materiales emitidos (lavas y piroclastos) y la evolución morfológica de sus depósitos (principalmente cono y campo de lavas), no se analizaron de forma sistemática. De nuevo, la erupción de La Serreta, Azores (19982001) sirve de ejemplo, ya que durante la misma una de las recomendaciones más importantes que se realizaron por el comité científico encargado de su estudio fue la realización de campañas batimétricas y de muestreos con una periodicidad de, al menos, una cada semana (Forjaz et al., 2000).

Con la erupción volcánica bastante avanzada (14 de noviembre 2011) el PEVOLCA buscó asesoramiento científico adicional incorporando expertos con amplia experiencia y conocimientos sobre el volcanismo de Canarias, tanto de la Estación Volcanológica de Canarias (IPNA-CSIC) como de las dos universidades canarias (ULL y ULPGC). Como primera consecuencia de la admisión de nuevos científicos al CECES, fue la desestimación de la idea que postulaba que la isla estaba partida mediante una falla en dos bloques enganchados y con desplazamiento diferencial, capaz de generar sismos de gran magnitud. Desechada esta idea que había justificado el cierre del túnel de Los Roquillos, éste se abrió de forma definitiva el 25 de noviembre 2011 (ver fig.
14). Asimismo, se planteó la necesidad de realizar campañas batimétricas y de toma de muestras de los materiales volcánicos con una periodicidad semanal. A pesar de esta reiterada demanda, nunca se llevaron a cabo (véase en el apartado de evolución morfológica del área eruptiva y en la figura 14 el espaciado temporal irregular de las campañas morfométricas por parte del B/O Ramón Margalef del IEO).

Desde finales de noviembre se redujo el número de terremotos registrados y la intensidad del tremor armónico. El 25 de noviembre 2011 se levantaron todas las restricciones viarias de la isla y los vecinos evacuados en diferentes áreas de la misma volvieron a sus casas. El 7 de diciembre 2011 el semáforo rojo de la crisis volcánica quedó restringido a la zona de exclusión marítima de 4 millas, pasando La Restinga y el resto de la isla de El Hierro a semáforo amarillo. La erupción volcánica se dio por finalizada oficialmente el 5 de marzo 2012 y cuatro días más tarde (9 de marzo de 2012) se redujo la zona de exclusión marítima de 4 millas a solo 0,5 millas de radio alrededor del centro emisor. Finalmente, el 19 de abril 2012 se cambió el semáforo de alerta volcánica a color verde para el territorio insular de El Hierro, dejando el color amarillo solo para el área de exclusión marítima (Gobierno de Canarias, 2011-2012. Comunicados de prensa de 25 noviembre y 7 diciembre 2011, y de 9 de marzo y 19 de abril 2012) (ver fig. 14).

\section{Conclusiones}

La erupción submarina de 2011-12 en El Hierro se ha ajustado a las previsiones científicas basadas en el conocimiento detallado de la geología de El Hierro, en particular, y de Canarias, en general. Ha ocurrido en la isla más joven del archipiélago, en los flancos submarinos de su edificio insular, donde existe mayor número de erupciones volcánicas que en la parte emergida, y en uno de los rifts (el S), en el que se concentra la mayor parte del volcanismo reciente de la isla.

Esta erupción ha generado un cono principal y varios adventicios alineados en la directriz estructural del rift $\mathrm{S}$, desde los que surgieron campos de lava que rápidamente eran canalizados por un valle submarino hacia profundidades superiores a los $1000 \mathrm{~m}$. La profundidad de la cima del cono principal se ha mantenido casi hasta el final de la erupción a más de $100 \mathrm{~m}$, imposibilitando el desarrollo de mecanismos explosivos de tipo surtseyano. Al 
contrario, las características de esta erupción han sido muy similares a las descritas en la de La Serreta (1998-2001) en la isla de Terceira (Azores), de muy baja explosividad y para la que se acuñó el término de erupción serretiana (Forjaz et al., 2000). Por tanto, puede afirmarse que la erupción de El Hierro de 2011-12 ha sido submarina fisural de tipo serretiano.

Durante esta erupción se han emitido a la superficie diferentes materiales volcánicos flotantes. Inicialmente fueron bombas y escorias con un relleno de un material blanco poroso, nunca antes observadas en el momento de su formación. El material de relleno de estas bombas volcánicas, rápidamente bautizadas como "restingolitas", se interpretó inicialmente como magma diferenciado (traquítico y riolítico), asociado a un proceso de mezcla de magmas que aumentaría la explosividad y peligrosidad de la erupción. Estudios más detallados de los núcleos blancos propusieron interpretarlos como "xenopómez", es decir, procedentes de sedimentos situados sobre la corteza oceánica, parcialmente fundidos y con suficiente flotabilidad para emerger por su elevada porosidad. Estas bombas con núcleo de origen sedimentario fueron reemplazadas al avanzar la erupción por lava balloons enteramente magmáticos, una vez consolidado el conducto eruptivo a través de los sedimentos oceánicos y aislados de ellos.

El registro de la sismicidad y deformación del terreno llevado a cabo con eficacia y constancia por el IGN, permitió la detección temprana de la erupción volcánica y determinar su emplazamiento submarino. Asimismo, el registro de la señal del tremor armónico ha determinado el conocimiento del inicio, desarrollo y final del proceso eruptivo.

Sin embargo, la interpretación de estos datos por el CECES ha sido muy controvertida. Se utilizó un modelo de tectónica de bloques especulativo como fuente potencial de terremotos importantes para justificar el cierre del túnel de Los Roquillos. No se previó o no se consideró necesaria la presencia de un buque oceanográfico y, una vez que éste llegó, ya avanzada la erupción, no realizó un seguimiento sistemático de la evolución morfológica del cono ni de la toma de muestras. En consecuencia, se tomaron medidas de protección civil posiblemente innecesarias que generaron grandes trastornos e inquietud en la población de la isla, así como cuantiosas pérdidas económicas, destacando entre ellas la evacuación de los habitantes de La Restinga en dos ocasiones. Paradójicamente, una erupción igualmente basáltica fisural como fue la del Teneguía
(La Palma) en el año de 1971, localizada en tierra, mucho más cercana a una población (Fuencaliente), y sin los medios instrumentales actuales, se manejó de forma eficaz y sencilla, sin recurrir a evacuaciones masivas ni cese alguno de la actividad económica en una isla mucho más poblada que El Hierro. Antes al contrario, dirigida por el profesor José María Fúster Casas (geólogo, catedrático de Petrología y Geoquímica de la Universidad Complutense de Madrid), la acertada gestión de la erupción evitó cualquier tipo de alarmismo catastrofista y generó, en su corta duración (del 26 de octubre al 28 de noviembre, 1971), importantes beneficios económicos al aumentar la imagen turística de La Palma.

De acuerdo con lo expuesto, este episodio eruptivo ha puesto de manifiesto que se dispone de una infraestructura técnica y humana adecuada para la detección temprana y seguimiento de crisis eruptivas en Canarias, pero que por encima de ello deben evitarse comportamientos excluyentes en la participación científica de los comités asesores.

\section{AGRADECIMIENTOS}

Agradecemos las detalladas correcciones de Robert I. Tilling, José López-Ruiz y un revisor anónimo, que han contribuido a mejorar sensiblemente el manuscrito, así como los comentarios de Andreas Klügel que han obrado el mismo efecto. Gracias a K. Pedroza y R. Hoffbauer por la cesión del análisis químico de la muestra de lava balloon basanítica. Nuestro agradecimiento a Raquel María Moreno Quesada y Jorge Enrique Fernández Machín, de El Pinar, por su apoyo logístico durante las campañas de campo en El Hierro y a los vecinos de La Restinga, por proporcionar muestras de las "restingolitas". Por último, agradecemos a la ULPGC la financiación de las campañas Guayota, a Antonio González Ramos (SIANI, ULPGC) el apoyo logístico y científico durante la toma de imágenes del ROV y a la tripulación del B/O Atlantic Explorer el trato dispensado. Este trabajo forma parte del proyecto SolSubC20081000047 financiado por el Gobierno de Canarias.

\section{Referencias}

Aparicio, A.; Bustillo, M.A.; Garcia, R. \& Araña, V. (2006). Metasedimentary xenoliths in the lavas of the Timanfaya eruption (1730-1736, Lanzarote, Canary Islands): metamorphism and contamination processes. Geological Magazine, 143: 181-193. doi:10.1017/ S0016756806001713

Aparicio, A.; Tassinari, C.C.G.; Garcia, R. \& Araña, V. (2010). Sr and Nd isotope composition of the metamorphic, sedimentary and ultramafic xenoliths of Lanzarote (Canary Islands): Implications for magma sources. Journal of Volcanology and Geothermal 
Research, 189: 143-150. doi:10.1016/j.jvolgeores.2009.10.017

Carracedo, J.C. (1994). The Canary Island: an example of structural control on the growth of large oceanicisland volcanoes. Journal of Volcanology and Geothermal Research, 60: 225-241. doi:10.1016/03770273(94)90053-1

Carracedo, J.C.; Day, S.; Guillou, H.; Rodriguez-Badiola, E.R.; Canas, J.A. \& Perez-Torrado, F.J. (1998). Hotspot volcanism close to a passive continental margin: The Canary Islands. Geological Magazine, 135: 591-604. doi:10.1017/S0016756898001447

Carracedo, J.C.; Day, S.; Guillou, H. \& Gravestock, P. (1999). Later stages of volcanic evolution of La Palma, Canary Islands: Rift evolution, giant landslides, and the genesis of the Caldera de Taburiente. Geological Society of America Bulletin, 111: 755-768. doi:10.1130/0016-7606(1999)111<0755:LSO$\mathrm{VEO}>2.3 . \mathrm{CO} ; 2$

Carracedo, J.C.; Rodriguez-Badiola, E.; Guillou, H.; de la Nuez, J. \& Perez-Torrado, F.J. (2001). Geology and volcanology of La Palma and El Hierro, Western Canaries. Estudios Geológicos, 57: 171-295.

Carracedo, J.C.; Pérez-Torrado, F.J.; Ancochea, E.; Meco, J.; Hernán, F.; Cubas, C.R.; Casillas, R. \& Rodríguez-Badiola, E. (2002). Cenozoic volcanism: II the Canary Islands. In: The Geology of Spain (Gibbons, F.A.W. \& Moreno, T., eds.), Geological Society of London, Londres, 438-472.

Carracedo, J.C.; Rodriguez-Gonzalez, A.; Perez-Torrado, F.J. \& Fernandez-Turiel, J.L. (2011). Crisis sísmica de 2011 en El Hierro: ¿Crónica de una erupción anunciada? Enseñanza de las Ciencias de la Tierra, 19: 216220.

Carracedo, J.C.; Perez-Torrado, F.J.; Rodriguez-Gonzalez, A.; Fernandez-Turiel, J.L.; Klügel, A.; Troll, V.R. \& Wiesmaier, S. (2012a). The ongoing volcanic eruption of El Hierro, Canary Islands. EOS, 93-9: 89-90.

Carracedo, J.C.; Perez-Torrado, F.J.; Rodriguez-Gonzalez, A.; Soler, V.; Fernandez-Turiel, J.L.; Troll, V.R. \& Wiesmaier, S. (2012b). The 2011 submarine eruption in El Hierro (Canary Islands). Geology Today, 28-2: 53-58.

Clague, D.A.; Davis, A.S.; Bischoff, J.L.; Dixon, J.E. \& Geyer, R. (2000). Lava bubble-wall fragments formed by submarine hydrovolcanic: explosions on L(o)overbar'ihi Seamount and Kilauea Volcano. Bulletin of Volcanology, 61: 437-449.

Coello, J.J. (2011). Sobre el origen de la 'restingolita', Actualidad Volcánica de Canarias. Noticias, 10 Oct., $2011 \mathrm{http}: / / \mathrm{www}$. avcan.org/varios/Informe_restingolitas.pdf.

Criado, C. \& Dorta, P. (2003). An unusual 'blood rain' over the Canary Islands (Spain). The storm of January 1999. Journal of Arid Environments, 55: 765-783. doi:10.1016/S0140-1963(02)00320-8

Darias Padrón, D.V. (1929). Noticias generales sobre la historia de la isla de El Hierro. Imprenta de M. Curbelo, La Laguna (Tenerife), 407 pp.

Donovan, A. \& Oppenheimer, C. (2012). Governing the lithosphere: Insights from Eyjafjallajökull concerning the role of scientists in supporting decision-making on active volcanoes. Journal of Geophysical Research, 117. doi:10.1029/2011JB009080.

Donovan, A.; Oppenheimer, C. \& Bravo, M. (2012). Science at the policy interface: volcano-monitoring technologies and volcanic hazard management. Bulletin of Volcanology, doi: 10.1007/s00445-0120581-5.

Forjaz, V.H.; Rocha, F.M.; Medeiros, J.M.; Menezes, L. \& Sousa, C. (2000). Noticias sobre o Vulcão Oceánico da Serreta, Ilha Terceira dos Açores. Observatorio Vulcanológico e Geotérmico dos Açores, Publicaçao $\mathrm{n}^{\mathrm{o}} 10,41 \mathrm{pp}$.

Gaspar, J.L.; Queiroz, G.; Pacheco, J.M.; Ferreira, T.; Wallenstein, N.; M.H., A. \& Coutinho, R. (2003). Basaltic lava balloons produced during the 1998-2001 Serreta Submarine Ridge eruption (Azores). In: Subaqueous Explosive Volcanism (White, J.; Clague, D. \& Smellie, J., eds.), American Geophysical Union, Washington, DC, ETATS-UNIS, 205-212.

Gee, M.J.R.; Masson, D.G.; Watts, A.B. \& Allen, P.A. (1999). The Saharan debris flow: an insight into the mechanics of long runout submarine debris flows. Sedimentology, 46: 317-335. doi:10.1046/j.13653091.1999.00215.x

Geist, D. \& Garcia, M.O. (2000). Role of science and independent research during volcanic eruptions. Bulletin of Volcanology, 62: 59-61. doi:10.1007/ s004450050291

Gimeno, D. (2011). Informe realizado para el Ayuntamiento de El Pinar, El Hierro, Islas Canarias, sobre un piroclasto de la erupción en curso, Informe Interno, 10 Oct 2011.

Gobierno de Canarias (2011-2012). Fenómeno sismovolcánico en El Hierro. Comunicados de prensa. http://www.gobiernodecanarias.org/dgse/sismo_hierro.html

Guillou, H.; Carracedo, J.C.; Perez-Torrado, F.J. \& Rodriguez Badiola, E. (1996). K-Ar ages and magnetic stratigraphy of a hotspot-induced, fast grown oceanic island: El Hierro, Canary Islands. Journal of Volcanology and Geothermal Research, 73: 141-155. doi:10.1016/0377-0273(96)00021-2

Hansteen, T.H.; Klugel, A. \& Schmincke, H.U. (1998). Multi-stage magma ascent beneath the Canary Islands: evidence from fluid inclusions. Contributions to Mineralogy and Petrology, 132: 48-64. doi:10.1007/ s004100050404

Hansteen, T.H. \& Troll, V.R. (2003). Oxygen isotope composition of xenoliths from the oceanic crust and volcanic edifice beneath Gran Canaria (Canary Islands): consequences for crustal contamination of ascending magmas. Chemical Geology, 193: 181-193. doi:10.1016/S0009-2541(02)00325-X

Hernández-Pacheco, A. (1982). Sobre una posible erupción en 1793 en la isla de El Hierro (Canarias). Estudios Geológicos, 38: 15-25.

Klugel, A.; Schmincke, H.U.; White, J.D.L. \& Hoernle, K.A. (1999). Chronology and volcanology of the 1949 multi-vent rift-zone eruption on La Palma 
(Canary Islands). Journal of Volcanology and Geothermal Research, 94: 267-282. doi:10.1016/S03770273(99)00107-9

Krastel, S. \& Schmincke, H.U. (2002). Crustal structure of northern Gran Canaria, Canary Islands, deduced from active seismic tomography. Journal of Volcanology and Geothermal Research, 115: 153-177. doi:10.1016/S0377-0273(01)00313-4

Kueppers, U.; Nichols, A.R.L.; Zanon, V.; Potuzak, M. \& Pacheco, J.M.R. (2012). Lava balloons-peculiar products of basaltic submarine eruptions. Bulletin of Volcanology, doi: 10.1007/s00445-012-0597-x

Longpre, M.A.; Chadwick, J.P.; Wijbrans, J. \& Iping, R. (2011). Age of the El Golfo debris avalanche, El Hierro (Canary Islands): New constraints from laser and furnace (40)Ar/(39)Ar dating. Journal of Volcanology and Geothermal Research, 203: 76-80. doi:10.1016/j.jvolgeores.2011.04.002

Marin, B. (2011). How not to handle a volcanic eruption. EL PAIS.com in English (20/10/2011) http://www. elpais.com/articulo/english/How/not/to/handle/volcanic/eruption/elpepueng/20111031elpeng_4/Ten.

Masson, D.G., (ed.) (1998). RRS Charles Darwin cruise 108, 14 Sep-16 Oct 1997. TOBI and MULTIBEAM surveys of submarine landslides around the Canaries. Southampton Oceanography Centre Cruise Report, Inglaterra, $35 \mathrm{pp}$.

Masson, D.G.; Watts, A.B.; Gee, M.J.R.; Urgeles, R.; Mitchell, N.C.; Le Bas, T.P. \& Canals, M. (2002). Slope failures on the flanks of the western Canary Islands. Earth-Science Reviews, 57: 1-35. doi:10.1016/S00128252(01)00069-1

McLeod, P. \& Sparks, R.S.J. (1998). The dynamics of xenolith assimilation. Contributions to Mineralogy and Petrology, 132: 21-33. doi:10.1007/s004100050402

McNutt, S.R.; Rymer, H. \& Stix, J. (2000). Synthesis of volcano monitoring. In: Encyclopedia of Volcanoes (Sigurdsson, H.; Houghton, B.; McNutt, S.R.; Rymer, H. \& Stix, J., eds.), Academic Press, San Diego, 11651183.

Mitchell, N.C. (1993). A model for attenuation of backscatter due to sediment accumulations and its application to determine sediment thickness with GLORIA sidescan sonar. Journal of Geophysical Research-Solid Earth, 98: 22477-22493. doi:10.1029/93JB02217

Pellicer, J.M. (1979). Estudio geoquímico del vulcanismo de la isla de El Hierro (archipiélago Canario). Estudios Geológicos, 35: 15-29.

Perez-Torrado, F.J.; Rodriguez-Gonzalez, A.; Carracedo, J.C.; Fernandez-Turiel, J.L.; Guillou, H.; Hansen, A. \& Rodríguez Badiola, E. (2011). Edades C-14 Del Rift ONO de El Hierro (Islas Canarias). In: El Cuaternario en España y Áreas Afines, Avances en 2011 (Turu, V. \& Constante, A., eds.), Asociación Española para el Estudio del Cuaternario (AEQUA), Andorra, 101-104.

Perugini, D.; Poli, G.; Petrelli, M.; De Campos, C.P. \& Dingwell, D.B. (2010). Time-scales of recent Phlegrean Fields eruptions inferred from the application of a 'diffusive fractionation' model of trace elements.
Bulletin of Volcanology, 72: 431-447. doi:10.1007/ s00445-009-0329-z

Rodriguez-Gonzalez, A.; Perez-Torrado, F.J.; FernandezTuriel, J.L.; Carracedo, J.C.; Gimeno, D.; Guillou, H.; Paris, R.; Hansen, A. \& Aulinas, M. (2011). Modelado morfológico y morfométrico de erupciones volcánicas recientes generando plataformas costeras: Caso estudio volcán de Montaña del Tesoro (El Hierro, Islas Canarias). In: El Cuaternario en España y Áreas Afines, Avances en 2011 (Turu, V. \& Constante, A., eds.), Asociación Española para el Estudio del Cuaternario (AEQUA), Andorra, 105-108.

Schmincke, H.U. (2004). Volcanism. Springer-Verlag, Berlín, 324 pp. doi:10.1007/978-3-642-18952-4

Schmincke, H.U. \& Graf, G. (2000). DECOS/OMEX II, Cruise $N^{o}$ 43, METEOR-Berichte 20001. Univ. Hamburg, Alemania, $99 \mathrm{pp}$.

Schmincke, H.U.; Klugel, A.; Hansteen, T.H.; Hoernle, K. \& van den Bogaard, P. (1998). Samples from the Jurassic ocean crust beneath Gran Canaria, La Palma and Lanzarote (Canary Islands). Earth and Planetary Science Letters, 163: 343-360. doi:10.1016/S0012821X(98)00168-X

Stillman, C.J.; Fuster, J.M.; Bennellbaker, M.J.; Munoz, M.; Smewing, J.D. \& Sagredo, J. (1975). Basal complex of Fuerteventura (Canary-Islands) is an oceanic intrusive complex with rift-system affinities. Nature, 257: 469-471. doi:10.1038/257469a0

Tilling, R.I. (2008). The critical role of volcano monitoring in risk reduction. Advances in Geosciences, 14: 3-11 doi:10.5194/adgeo-14-3-2008

Troll, V.R.; Klügel, A.; Longpré, M.A.; Burchardt, S.; Deegan, F.M.; Carracedo, J.C.; Wiesmaier, S.; Kueppers, U.; Dahren, B.; Blythe, L.S.; Hansteen, T.H.; Freda, C.; Budd, D.A.; Jolis, E.M.; Jonsson, E.; Meade, F.C.; Harris, C.; Berg, S.E.; Mancini, L.; Polacci, M. \& Pedroza, K. (2012). Floating stones off El Hierro, Canary Islands: xenoliths of pre-island sedimentary origin in the early products of the October 2011 eruption. Solid Earth, 3: 97-110. doi:10.5194/se-3-97-2012

Urgeles, R.; Canals, M.; Baraza, J. \& Alonso, B. (1998). Seismostratigraphy of the western flanks of El Hierro and La Palma (Canary Islands): A record of Canary Islands volcanism. Marine Geology, 146: 225-241. doi:10.1016/S0025-3227(97)00130-8

Urgeles, R.; Canals, M.; Baraza, J.; Alonso, B. \& Masson, D. (1997). The most recent megalandslides of the Canary Islands: El Golfo debris avalanche and Canary debris flow, west El Hierro island. Journal of Geophysical Research-Solid Earth, 102: 20305-20323. doi:10.1029/97JB00649

Ye, S.; Canales, J.P.; Rihm, R.; Danobeitia, J.J. \& Gallart, J. (1999). A crustal transect through the northern and northeastern part of the volcanic edifice of Gran Canaria, Canary Islands. Journal of Geodynamics, 28: 3-26. doi:10.1016/S0264-3707(98)00028-3

Recibido el 10 de enero de 2012 Aceptado el 17 de mayo de 2012 Publicado online el 11 de junio de 2012 